\title{
La práctica psiquiátrica a través de las tesis de medicina en Puebla durante el porfiriato
}

\author{
The Practice of Psychiatry Through \\ the Thesis of the Colegio de Medicina \\ del Estado de Puebla during the Porfirian regime
}

\author{
Andreé Bojalil Daou \\ Centro de Investigación y Docencia Económicas (CIDE) \\ andree.bojalil@gmail.com
}

\begin{abstract}
Resumen
Los estudiantes de medicina de Puebla durante el porfiriato elaboraron seis tesis enfocadas a la psiquiatría. En estos estudios observamos que adoptaron corrientes europeas, especialmente francesas, que los ayudarían, a la larga, a desarrollar su práctica médica, pero que al mismo tiempo trataron de enfocarse en problemas locales. A través del estudio del sistema educativo en México y en Puebla, así como los autores referenciados por los maestros y alumnos, trataremos de demostrar que buscaron encontrar soluciones a los problemas de la modernidad, como el alcoholismo y la histeria, y propusieron innovaciones en materia terapéutica.
\end{abstract}

Palabras clave: psiquiatría, histeria, alcoholismo, tesis, estudiantes de medicina, Puebla.

\begin{abstract}
Medical students in Puebla during the Porfirian regime elaborated six theses focused on psychiatry. In these studies, we observe that they adopted European theories, especially from France, that helped them to develop their future medical practice, but also that they tried to solve some local problems. Through the study of the educational system in Mexico and in Puebla, as well as of the authors referred to by the teachers and the students, we suggest that they were seeking for solutions for the modernity health problems such as alcoholism and hysteria and, at the same time, they proposed some therapeutic innovations.
\end{abstract}

Abstract

Keywords: psychiatry, hysteria, alcoholism, thesis, medical students, Puebla. 
En 1879, el Reglamento para el Gobierno Interior de la Escuela de Medicina y Farmacia del estado de Puebla (artículo 133, capítulo XIX), establecía que para obtener el título de médico, cirujano y partero era necesario que los estudiantes fueran examinados por cinco catedráticos médicos al final de sus estudios. Los alumnos tendrían que cubrir tres requisitos que incluían, el primer día, un examen oral sobre la disertación o tesis presentada por el candidato, o sobre cualquier punto referente a la parte teórica de las materias enseñadas en la escuela; el segundo día, un examen teórico por parte de los profesores de clínica mediante la exploración de algunos enfermos y, finalmente, el tercer día, un examen práctico con demostraciones anatómicas y operaciones quirúrgicas realizadas sobre un cadáver.

Además, se instituía que los alumnos que quisieran examinarse serían responsables de entregar, al realizar la última inscripción a sus cursos, un escrito en el que propusieran una disertación original que habrían de escribir ellos mismos sobre los puntos que eligieran, pero que siempre estuvieran apoyados por observaciones personales. Al entregar la solicitud de examen final, los estudiantes deberían acompañarla con un ejemplar de este escrito para cada uno de los sinodales, y uno para la secretaria, que se archivaría en el expediente del alumno, dos para la biblioteca de la escuela y uno para la Dirección.

En las tres décadas que abarcó el periodo conocido como porfiriato, 54 alumnos recibieron el título. Sus trabajos de investigación tocaron diferentes temáticas, a través de la clínica y, poco a poco, fueron enfocándose en los problemas de salud más comunes de la época, tanto en México como en Europa. Entre los cuales destacan los relacionados con cuestiones de lactancia, ginecología, sífilis, prostitución, cardiología, antisepsia, tuberculosis, paludismo, plantas medicinales, pediatría, higiene, cólera, mortalidad y cáncer; solamente seis enfocadas en enfermedades mentales como el alcoholismo, la histeria y la psiquiatría óptica. ${ }^{1}$

A excepción de uno, los estudiantes interesados en los temas de salud mental, a diferencia de sus compañeros, no recibieron una educación formal en esta cuestión, sin embargo, fue a través de la medicina legal como llegaron al conocimiento. La cátedra de enfermedades mentales empezó casi finalizada la década de 1890; no obstante, el interés de los que serían los representantes de la práctica psiquiátrica en Puebla en el porfiriato estuvo latente desde mucho tiempo atrás. Aunque representan apenas un poco más del 10 por ciento del total de las tesis elaboradas en estas casi tres décadas, los alumnos que escribieron estos trabajos se preocuparon por los crecientes problemas que enfrentaba el país y el estado de Puebla, en materia de higiene mental y social, como el alcoholismo, la pereza y la ignorancia. La tan ansiada modernidad se enfocó en la creación de infraestructura, la reforma de la propiedad rural, la estabilidad económica y, especialmente, en el mejoramiento de las condiciones de vida de la población, que, a la par del crecimiento económico, intensificó lo que se conside-

\footnotetext{
${ }^{1}$ Estas tesis se encuentran en la Biblioteca Histórica José María Lafragua de la BUAP (en adelante Lafragua) que cuenta con un índice de 54 tesis de medicina que abarcan desde 1879 hasta 1910.
} 
raba en la época como problemas de higiene y costumbres viciosas. ${ }^{2}$ Algunos autores, como Samuel Morales y Secundino Sosa (1888), atribuyeron problemas como el alcoholismo a las malas costumbres en la ingesta de bebidas "espirituosas", debido a la falta de educación de la población, y respecto de la histeria y la locura, encontraban sus orígenes en los hábitos y la herencia. ${ }^{3}$

Teniendo esto en mente, el objetivo del presente trabajo es demostrar que, si bien la enseñanza de la medicina europea contribuyó a la consolidación del conocimiento, los alumnos que escribieron estas disertaciones también trataron de buscar una explicación y solución a los problemas en la Puebla del porfiriato, no sólo a partir de sus tesis, sino más adelante mediante su práctica profesional. Estos alumnos desarrollaron trabajos científicos que iban a la par con los de sus contemporáneos, mediante los cuales demuestran que, a pesar de tener una fuerte influencia de autores europeos, también lograron desarrollar una visión propia. Esta última, aunque conceptualizada bajo los ojos de la medicina del viejo continente, respondía a necesidades locales y nacionales que los llevaban a buscar una solución a problemas frecuentemente citados por intelectuales y autoridades, como la pobreza, la vagancia, la pereza, la ausencia laboral, la mala situación económica, la violencia intrafamiliar, así como la falta de educación en la población, entre otras.

Historiográficamente, este tema ha representado un debate que, como lo plantea Frida Gorbach (2013), coloca a estas investigaciones en una dicotomía entre el difusionismo y la historia de la ciencia en México que ha sido difícil de romper. Como la autora señala, la teoría difusionista ha tendido a buscar en esta relación "centro-periferia" los orígenes de los desarrollos científicos en los países no europeos, y es a partir de su cercanía con el centro como la periferia determina su lugar.

Por otra parte, la historia de la ciencia en México ha tendido a dar un enfoque totalmente particularista a la producción científica, tomando como origen el siglo XVII y desarrollando una historia completamente independiente de sus contemporáneos europeos. Probablemente, la crítica más fuerte recibida es que su base parte de la consolidación del Estado mexicano y de ahí se considera la formación de sus instituciones, como si éstas dependieran completamente de los desarrollos políticos en el país. Como lo plantea Gorbach, el difusionismo se

\footnotetext{
${ }^{2}$ Estos problemas fueron tratados por Guerrero (1901) y Roumagnac (1904), quienes hicieron un fuerte énfasis en la relación que existía entre el alcoholismo y la criminalidad.

${ }^{3}$ Este trabajo es muy interesante, ya que en muestra, de una manera muy completa, la tendencia higienista de la época. En éste se dieron a conocer sus investigaciones sobre las condiciones higiénicas de la ciudad de Puebla, que abarcaban desde la atmósfera, suelos, aguas y otros aspectos naturales y la influencia que causaban en la salud de los poblanos. Pusieron especial énfasis en las costumbres, apuntando a las condiciones antihigiénicas y lo deseable respecto de la alimentación, bebida, vestido y medicamentos. Profundizaron en las condiciones laborales y ambientales de los obreros y su correlación con las enfermedades que sufrían. Encontraron la etiología de las enfermedades en la educación, costumbres, alimentación y herencia proponiendo, después de esta revisión, conceptos higiénicos y prácticas urgentes para resolver los problemas sanitarios de Puebla.
} 
visualizaría como si una corriente científica se implantara en un campo vacío, mientras que la historia nacional de la ciencia obviaría por completo la influencia extranjera para el caso mexicano.

A la luz de este debate, consideraremos este estudio como un lugar en el que ambas posturas pueden dialogar sin necesidad de excluirse ni desacreditarse. Queremos mostrar en las páginas subsiguientes que los estudiantes poblanos de medicina utilizaron como base los estudios europeos para enfrentar los problemas sociales, higiénicos, laborales y de salud en México, pero a su vez desarrollaron de igual modo una visión propia en cuanto a las características muy particulares que presentaban. Esto los llevó a atender a los enfermos desde su práctica médica particular, pero, al mismo tiempo, a aprovechar los avances científicos y teóricos de otras partes del mundo.

Nuestro objeto de estudio son las tesis de psiquiatría, que si bien han sido referenciadas en la historiografía de la medicina o de su enseñanza, casi siempre son consideradas una fuente subordinada a las publicaciones de libros y revistas médicas. Partiremos de dichos textos para entender cómo era la formación de los médicos a finales del siglo XIX, sobre todo para comprender qué autores y metodologías eran consideradas por ellos como las mejores, que sabemos influyeron en su práctica profesional.

Recordemos que los estudiantes son un grupo de "intelectuales en formación", el cual, al carecer de la experiencia de sus maestros, se deja guiar por ellos, pero al mismo tiempo llegan al conocimiento por medios propios. Para entender su práctica como profesionistas, hablaremos en principio de la historia de la enseñanza de la medicina en México, y luego en Puebla, para después revisar los planes de estudio y las fuentes consultadas que llevarían a la culminación de su carrera y su posterior práctica profesional. Como lo propone Rosa María Fernández (2015: 2), estos escritos no son simplemente un requisito para obtener un grado académico, sino que encierran la memoria intelectual de una colectividad, en este caso, los psiquiatras poblanos del porfiriato.

\section{La enseñanza de la medicina en México y en Puebla}

Cuando se habla de educación en el siglo XIX, es innegable la influencia que tuvo el Estado sobre aquélla, ya que los diferentes hechos políticos se reflejaron en el cambio y propósito de las instituciones encargadas de la salud y de la educación en todo el país. A unos años de consumada la Independencia, la Ley de Instrucción Pública de 1833 instituyó la creación de una Dirección General de Instrucción Pública en la Ciudad de México, la cual incluía seis establecimientos de enseñanza superior, entre los que estaba el encargado de la educación médica (Zacarías-Prieto, 2015: 305). Dejando atrás a la Nacional y Pontificia Universidad, se creó el 
Establecimiento de Ciencias Médicas que, a lo largo de todo el siglo XIX, sufrió cambios producidos por la escasez de fondos debido a la lucha entre conservadores y liberales, los imperios, las invasiones y las guerras internas. Consecuencia de todo esto, el Colegio de Medicina tuvo diferentes sedes que pasaron desde el convento de Belén, el antiguo Convento y Hospital del Espíritu Santo, el Colegio de San Ildefonso, el Colegio de San Juan de Letrán, el ex Convento de San Hipólito, hasta el antiguo Palacio de la Inquisición y el Hospital General, desde 1905 (Zacarías-Prieto, 2015: 305-317).

Gracias a la influencia de varios intelectuales, el positivismo decimonónico poco a poco fue otorgando un carácter científico a la medicina. Aquél creaba una diferencia cuantitativa entre lo "normal" y lo "patológico", en la que la ausencia o sobrante de alguna característica reelaboraba la totalidad orgánica (Canguilhem, 1978: 19). En este contexto, los nuevos avances tecnológicos y científicos gradualmente fueron introducidos en la enseñanza médica que adoptó la anestesia y la radioterapia, la morfología comparada, el evolucionismo darwinista, la anatomía microscópica, la microbiología de Claude Bernard, el éxito de las vacunas de Pasteur, así como de Koch y sus investigaciones sobre la tuberculosis, Ignác Semmelweis y el descubrimiento de la fiebre puerperal y la teoría celular, entre otras.

Probablemente, la transformación más importante en materia médica fue el cambio sistemático de la clínica clásica a la clínica moderna francesa, a mediados de siglo. Se pasó de una recopilación superficial de signos y síntomas a una definición más concreta del lenguaje que apelaba a las transformaciones internas, morfológicas y funcionales del cuerpo cambiando el concepto de enfermedad (Cárdenas et al., 2015: 292; Martínez, 2003: 89). Como resultado, se definieron nuevos padecimientos con una base más racional, y localizados en lugares específicos, que serían identificados de una manera sistemática a través de la observación en los hospitales mexicanos. Con base en lo anterior, conforme transcurrió el siglo, se asentaron las bases para las especialidades médicas que, a finales del siglo XIX, en México ya incluían la oftalmología, la ginecología, la bacteriología y las enfermedades mentales (Zacarías-Prieto, 2015: 316).

Además, durante el porfiriato, la Escuela Nacional de Medicina, ahora dependiente de la Secretaría de Justicia e Instrucción Pública, también mantuvo relaciones con otras instancias. De la Secretaría de Gobernación dependían la beneficencia pública y el Consejo Superior de Salubridad, encargados de las clases prácticas en los hospitales de beneficencia y de la clase de higiene, respectivamente; la Secretaría de Instrucción Pública normaba la enseñanza a través del Consejo Superior de Instrucción Pública, el Museo Anatomo-Patológico y los institutos Patológico y Bacteriológico Nacional; la Escuela Práctica Médico Militar, estaba subordinada a la Secretaría de Guerra y Marina; la Secretaría de Relaciones Exteriores se encargaba de informar sobre los adelantos en ciencias médicas y de registrar los estudios de especialización que hacían los médicos mexicanos en el extranjero; y con la Suprema Corte de Justicia, 
porque muchos de los catedráticos fungían como peritos en juicios criminales si era necesario (Carrillo y Saldaña, 2005: 259-260).

Recordemos que el régimen porfirista buscó homogeneizar la atención pública en aspectos de salud por lo que, si en la capital del país se creó un Consejo de Salubridad Pública, primero en Puebla, y después en los otros estados, progresivamente, se fundaron sus homólogos que trabajaron por velar por la salud de la población, también a través de la beneficencia pública. El incremento en la demografía de las ciudades, gracias a la demanda de mano de obra que produjo la industrialización del país, vino acompañado del hacinamiento y las carencias higiénicas y condiciones insalubres de vivienda y trabajo que había que atender constantemente. Así, los médicos poblanos que se habían formado antes del porfiriato, poco a poco se adaptaron a las innovaciones científicas y metodológicas, pero también a las demográficas y laborales que implicaban un nuevo reto en la atención sanitaria.

Aunque no soslayamos el aspecto privado, los galenos poblanos del último tercio del siglo XIX aprendieron de sus maestros, a su vez que desarrollaron su práctica médica mediante la asistencia social con acciones como la prevención de epidemias mediante las campañas de vacunación; las visitas de supervisión a los establecimientos públicos, industriales y mercantiles; participando en la creación de nuevos reglamentos para los establecimientos de beneficencia que normaran las condiciones de vida de sus asilados, así como de reglamentos para la profesión de médicos legales, generales y de parteras; algunos se convirtieron en el "médico experto" que asistía a las veinte cabeceras de los distritos foráneos; otros participaron en los diferentes congresos internacionales de higiene, y otros más se volvieron investigadores (Cortés, 2010: 176-180).

En este contexto, observamos que, a la par con la ciudad de México, la influencia de la medicina francesa llegó a Puebla a mediados del siglo XIX, pero, al mismo tiempo, paulatinamente se adaptó, pero con matices locales. Sin embargo, su enseñanza empezó mucho antes. Las cátedras, para los que no podían viajar a la capital para formarse como galenos, boticarios y parteras, iniciaron de manera informal en el Hospital de San Pedro ${ }^{4}$ en 1814. Frente a esto, la ley del 6 de junio de 1831, relativa al ejercicio y estudio de la medicina, buscaba que la práctica médica se reglamentara, por lo que por primera vez se crearon, formalmente, las clases de medicina en la ciudad. Al final de los cinco años de materias, tendrían que presentar un examen sobre teoría, el primer día, y otro práctico, al día siguiente (Castro, 2009: 5).

En los años siguientes fueron muy pocos los cambios a la reglamentación, no obstante, llegaron a partir de 1856, cuando el plan se amplió a siete años, cursando once materias. Al igual que en el plan anterior, las clases con una base teórica se ofrecerían en el Colegio del Estado, las

\footnotetext{
${ }^{4}$ El Hospital real de San Pedro se fundó en 1544 para dar atención a indígenas y mestizos enfermos. Con el paso de los años, este nosocomio se volvió la base para la atención médica en la ciudad, llegando a ser la sede de la Academia Médico Quirúrgica de Puebla en el siglo XIX.
} 
prácticas en el Hospital de San Pedro y los aspirantes sólo podrían ingresar a la carrera después de avalar sus estudios de filosofía y francés (Castro, 2009: 6). Desde este momento, la institución encargada de la instrucción teórica y práctica recibiría el título de Colegio de Medicina, y estaría regida por una Junta Directiva, que crearía una nueva clase de profesionistas: los médicos poblanos.

La segunda mitad del siglo xIx fue complicada para la Escuela de Medicina de Puebla, ya que sufrió varias crisis económicas y cambios en su estructura. La Intervención Francesa y el Segundo Imperio, por ejemplo, propiciaron que se cerrara la escuela varias veces, ya fuera porque la ciudad se encontraba sitiada, o por órdenes del mismísimo emperador ${ }^{5}$ (Cortés y Palacios, 2012: 188). Maximiliano de Habsburgo encargó el cuidado de estos establecimientos a manos del gobierno municipal para vigilar directamente sus condiciones por lo que, tanto los hospitales de San Pedro, el de hombres dementes de Santa Rosa y el de mujeres dementes de San Roque, ${ }^{6}$ y la Escuela de Medicina, que era parte del Colegio del Estado de Puebla, ${ }^{7}$ cambiaron de manos. Tal vez, el que más sufrió fue el último que, después de ser evaluado por las autoridades a petición del emperador, tuvo que cerrar sus puertas cuatro años debido a que se argumentaba que no tenía los medios suficientes para la enseñanza (Zacarías-Prieto, 2015: 314).

La Reforma y el porfiriato, ambos de carácter liberal, mostraron un punto de quiebre en la concepción de país: la separación Iglesia-Estado y la estabilidad política después de 70 años de conflictos. Esto llevaría a la formación de una nación moderna basada en ideales positivistas. Las Leyes de Reforma dieron la responsabilidad de los establecimientos a cada Estado, por lo que, la beneficencia pública, de reciente creación, tomaría en sus manos la enseñanza y la asistencia de las clases más desprotegidas a través de escuelas, asilos, hospicios y hospitales (Lorenzo, 2011).

Este orden se mantuvo en el porfiriato, a través del Consejo de Salubridad, asignando, en 1879, su cuidado a una Junta Inspectora a cargo de la Secretaría de Fomento del Gobierno del Estado. Ello ayudó a la enseñanza, que se fortaleció gracias al ejercicio práctico-teórico, enfocando el presupuesto en crear aulas mejor amuebladas y equipadas con todo tipo de

\footnotetext{
${ }^{5}$ Según Zacarías-Prieto (2015: 313), la Escuela Nacional de Medicina cerró sus puertas debido al conflicto entre el proyecto liberal y conservador, en el que los médicos tenían que jurar lealtad al emperador. Para el caso de Puebla, atribuye su clausura al informe sobre la enseñanza de la medicina en este establecimiento, el cual resultó negativo, debido a que, según éste, se seguían arrastrando viejos vicios que imposibilitaban la enseñanza eficaz de la medicina.

${ }^{6}$ Los últimos dos fueron los encargados de la práctica psiquiátrica en la ciudad. El Hospital de San Roque fue fundado en el siglo XVı por Bernardino Álvarez, y su congregación, como un hospital para viajeros en su paso de Veracruz hacia la ciudad de México. Posteriormente, en algún momento del siglo XVII, se decidió enfocar sólo en enfermos mentales, lo que continuó hasta 1990. En 1863, se dejó a las mujeres únicamente en San Roque y a los hombres se les mandó al hospital de Santa Clara y, posteriormente, al Ex convento de Santa Rosa (Bojalil, 2013).

${ }^{7}$ El Colegio del Estado albergaba la Escuela de Medicina, la de Jurisprudencia, la de Agricultura y Veterinaria, así como la de Comercio.
} 
aparatos, más los gabinetes de bacteriología, el anfiteatro y el aumento de su acervo bibliográfico, a la par de la creación de los museos de Historia Natural y de Anatomía. Los médicos contemporáneos proponían que la medicina, estudiada y practicada en los hospitales que pertenecían a este sistema, entrara en el campo de las ciencias, terminando el enfrentamiento dialéctico entre el galenismo tradicional ${ }^{8}$ y la medicina científica, para dar paso a una medicina progresista consolidada por la fisiología experimental y estructurada por teorías y principios de la patología celular, de la histología, la ontogénesis y la evolución (Robles, 2012: 13-14).

Esto no salvó a la Escuela de Medicina de ser cerrada desde septiembre de 1885 hasta la segunda mitad de 1887, cuando el gobernador Rosendo Márquez ordenó ubicar ahí la Escuela de Artes y Oficios (Robles, 2012: 224). En los años posteriores a su reapertura, la formación de los futuros médicos sería a través de clases teóricas en las aulas, apoyadas con las clases prácticas en los hospitales y laboratorios con los que contaba la escuela. Como resultado, se formaron nuevos médicos, que a la larga se volverían los catedráticos de la institución. Doctores como Heliodoro González, Feliciano Hernández, Rafael Serrano, Francisco Martínez Vaca, Manuel y Fausto Vergara, Manuel Calva, Isaac del Río, Juan N. Quintana, que a su vez habían sido alumnos de personalidades como Joaquín Ibáñez, Francisco Marín, Manuel Mena, Leonardo Cardona, Plácido Díaz Barriga, Agustín Galindo, José María Marín, Bibiano Carrasco y Manuel Rivadeneyra trabajaron por hacer que la Escuela de Medicina creciera y se mantuviera a lo largo de los años, encontrando un nicho perfecto para el positivismo en Puebla.

\section{La influencia europea en los planes de estudio}

Los planes de estudio

En 1851, el plan de estudios (véase cuadro 1) se centró de una manera más profunda en el conocimiento teórico-práctico, mediante la clínica hospitalaria, que se convirtió en uno de los puntos centrales de la medicina. En ésta estaba presente el nuevo concepto de enfermedad que proponían las escuelas modernas o científicas europeas, por lo que los libros de texto hacían referencia a estos autores, en particular a los franceses (Robles, 2012: 169).

La adhesión al gobierno monárquico clausuró los colegios de medicina del país, incluyendo el de Puebla, para ser reabiertos y fortalecidos con el gobierno juarista y los nuevos ideales positivistas de la Escuela Nacional Preparatoria (Robles, 2012: 172). En Puebla, el

\footnotetext{
${ }^{8}$ El galenismo es un término que proviene del médico griego Galeno de Pérgamo (129-216 d.C.) que proponía que las enfermedades estaban causadas por la alteración de alguno de los cuatro humores: sangre, bilis, linfa y pituita. Esta teoría dominó la medicina occidental por más de mil años, hasta la creación del método científico.
} 
Cuadro 1

Plan de estudios, 1851-1893

\begin{tabular}{|c|c|c|c|}
\hline Año & $1851-1854$ & 1882 & 1893 \\
\hline \multirow[t]{3}{*}{$1^{\circ}$} & Anatomía descriptiva & Anatomía descriptiva & Anatomía descriptiva \\
\hline & Botánica & Histología & Histología normal \\
\hline & & Farmacia elemental & Materia médica \\
\hline \multirow[t]{4}{*}{$2^{\circ}$} & Anatomía descriptiva & Fisiología & Anatomía topográfica \\
\hline & Fisiología e higiene & Patología general & Fisiología \\
\hline & Farmacia & Patología externa I & Patología externa \\
\hline & & Clínica externa I & Clínica externa \\
\hline \multirow[t]{5}{*}{$3^{\circ}$} & Anatomía & Anatomía topográfica & Patología externa \\
\hline & Patología & Patología externa II & Patología interna \\
\hline & Clínica externa & Clínica externa II & Operaciones y aparatos \\
\hline & & Patología interna I & Clínica Interna \\
\hline & & Clínica interna I & \\
\hline \multirow[t]{6}{*}{$4^{\circ}$} & $\begin{array}{l}\text { Operaciones, partos de } \\
\text { mujeres y niños recién } \\
\text { nacidos }\end{array}$ & Patología interna II & Patología interna \\
\hline & Patología & Clínica interna II & Patología general \\
\hline & Clínica Interna & Operaciones y vendajes & Histología patológica \\
\hline & Materia médica & Terapéutica general y aplicada & Bacteriología \\
\hline & Medicina legal & & Clínica externa \\
\hline & & & Terapéutica y su clínica \\
\hline \multirow[t]{6}{*}{$5^{\circ}$} & $\begin{array}{l}\text { Operaciones, partos de } \\
\text { mujeres y niños recién } \\
\text { nacidos }\end{array}$ & Obstetricia & Obstetricia y su clínica \\
\hline & Patología & Clínica de obstetricia & Medicina legaly toxicología \\
\hline & Clínica Interna & Medicina legal & Higiene \\
\hline & Materia médica & Higiene & Enfermedades en niños \\
\hline & Medicina legal & & Clínica interna \\
\hline & & & Terapéutica general \\
\hline
\end{tabular}

establecimiento volvió a abrir sus puertas en 1869, impulsado por una serie de médicos que buscaban la creación de una academia propia, lo que desembocó en la fundación, entre 1874 y 1877, de la Sociedad Médico-Farmacéutica de Puebla, del periódico El Estudio, la apertura del hospital de niños de La Caridad y la Sociedad Médica "Miguel Jiménez", que serían los antecedentes para la primera Escuela de Medicina y Farmacia de Puebla, fundada en 1879 (Robles, 2012: 174-175). 
Estos cambios generaron que los médicos, ese mismo año, tuvieran el interés por reformar el plan de estudios que no había sido modificado desde $1856^{9}$ y que no pudo concretarse por completo hasta 1882. La base principal era tratar de hacerlo lo más parecido al de la Ciudad de México, por lo que el tiempo se redujo dos años y el orden de los cursos y las materias se modificaron. Únicamente se cursarían Anatomía y Terapéuticas por un año, en lugar de dos; se suprimirían las materias de Análisis Químico, Historia de la medicina, Anatomía Patológica y la Patología de la infancia, y la Histología se anexaría a la Anatomía descriptiva, evitando así la repetición de temas y sobre todo el cansancio de los alumnos que tendían a desertar e irse a estudiar a la capital (Cortés y Palacios, 2012: 199-200).

Como se señaló antes, los temas relacionados con las enfermedades mentales no estuvieron presentes en estos planes de estudios, lo que de por sí plantea una interrogante historiográfica, pues nos lleva a cuestionarnos si fueron autodidactas y sobre todo de dónde obtuvieron ciertos intereses. Casi ninguno de los tesistas que aquí revisaremos recibió una formación específica en dicho tema:, ${ }^{10}$ aun así, contamos con datos de un alumno que presentó un examen extraordinario de esta materia en 1890,11 lo que nos hace cuestionarnos sobre la metodología, pues fue hasta el plan de 1893, un año después de que el doctor Miguel Alvarado diera la primera cátedra de enfermedades mentales en la Escuela Nacional de Medicina, que apareció (Somolinos, 1976: 145). En los cinco años de estudios, las enfermedades mentales se revisarían en los cursos de patología interna de tercer año, en los de patología interna y general de cuarto año, así como en la de medicina legal y toxicología de quinto.

En patología interna se examinarían las enfermedades mentales en el apartado sobre el sistema nervioso y su problemática. Temas como "enfermedades mentales, enfermedades de las meníngeas cranianas, enfermedades del cerebro, enfermedades de la médula espinal, enfermedades de las meníngeas raquídeas, neurosis centrales, enfermedades de los nervios cerebro espinales, neurosis periféricas y enfermedades del simpático" ${ }^{12}$ se aprenderían a profundidad, dejando entrever la ya presente clasificación científica en materia de neurología y, sobre todo, el desarrollo de la clínica psiquiátrica.

\footnotetext{
${ }^{9}$ Como ya se indicó, este plan de estudios había aumentado de cinco a siete años, con once materias: Física médica; Historia natural médica; Anatomía descriptiva y elementos de Anatomía general; Fisiología y elementos de higiene; Elementos de patología general, externa y clínica quirúrgica; Patología interna y clínica médica; Operaciones, vendajes y Aparatos de cirugía; Terapéutica, Materia médica y Medicina legal; Obstetricia, enfermedades de mujeres paridas y niños recién nacidos; Farmacia teórica y práctica. Reglamento para el Estudio y Ejercicio de las Ciencias Médicas (1856: 4-5)

${ }^{10}$ Con esto nos referimos a clases especializadas en el tema, o a lo que unos cuantos años después sería la especialidad en psiquiatría.

${ }^{11}$ Lafragua, Escuela de Medicina, Actas de exámenes, Caja 2, exp.52. Este alumno fue examinado por los doctores José de Jesús Díaz, Juan A. Calderón y Ernesto Espinosa el 6 de noviembre de 1890.

12 Lafragua, Escuela de Medicina, Fondo Adquisición, 313-316.
} 
La patología general se encargaría de reafirmar lo ya aprendido en cuanto al sistema nervioso, así como la exploración de las facultades mentales, de las sensaciones y de los movimientos; el electrodiagnóstico; la semiótica y el diagnóstico de las enfermedades nerviosas. En la etiología ${ }^{13}$ de las enfermedades se analizaría la herencia; ${ }^{14}$ las causas físicas, mecánicas y químicas; parásitas, animales y vegetales, y las autointoxicaciones. También, los procesos morbosos como las alteraciones de la circulación de la sangre y de la linfa; la metamorfosis regresiva de la nutrición; la metamorfosis progresiva de la nutrición; la inflamación, y las neoformaciones de origen inflamatorio, tumores y deformaciones.

La materia de medicina legal y toxicología, de quinto año, era la que abordaba más a profundidad los problemas mentales, pues probablemente muchos de los egresados tendrían que fungir como médicos legistas o peritos en casos de responsabilidad criminal o civil de los enajenados. Este tema era muy cuestionado tanto por abogados como por médicos del porfiriato, ya que por una parte se alegaba que los enfermos mentales (ya fuera que sufrieran de alcoholismo o de cualquier otro padecimiento) eran inocentes de sus actos por no encontrarse en pleno uso de sus facultades, mientras que, por el otro, se decía que eran plenamente, o al menos parcialmente, responsables por haber cometido los actos en intervalos de razón ${ }^{15}$ (Bojalil, 2018b).

La cátedra incluía temas como "cuestiones particulares relativas a las personas de ordinario muertas; cuestiones generales a las personas de ordinario muertas: inhumaciones, exhumaciones y autopsias; cuestiones relativas a las personas de ordinario que se refieren a los órganos genitales: matrimonio, preñez, aborto, parto natural, partos precoces y tardíos, superfetación y delitos de incontinencia; cuestiones relativas a las personas de ordinario vivas que refieren a varios estados particulares: identidad, simulación y disimulación de enfermedades, seguros de vida, servicio militar y alteraciones mentales; nociones de antropología criminal; cuestiones que se refieren a las cosas: análisis de manchas, alteración de manuscrito, decoloración de los cabellos, que dejan entrever el creciente interés por las cuestiones criminales. ${ }^{16}$

El problema de la responsabilidad criminal de los enajenados asimismo se abordaba desde la Escuela de Leyes, que formaba también parte del Colegio del Estado de Puebla, y que reflejó el debate de la época que buscaba explicar no sólo las leyes fisiológicas, sino el

${ }^{13}$ La etiología es el estudio del origen de las enfermedades.

${ }^{14}$ Constitución y temperamento, aptitudes morbosas, edad, sexo, causas intrínsecas dinámicas.

${ }^{15}$ Por ejemplo, Hidalgo y Carpio decía que las persona que, embriagada, cometía un crimen, ignoraba lo que había puesto en juego, ya que carecía de razón para conocerlo, pero que, antes de embriagarse, conocía muy bien que en la embriaguez podía herir o matar y que se exponían voluntariamente al riesgo de hacerlo. De esta manera, podía concluirse que el que quería la causa quería el efecto, por lo que la herida o muerte hecha por su mano era voluntaria, por haberlo sido también su ignorancia. Como consecuencia, el delito era castigable, si bien mucho menos que el del hombre que estaba en su juicio, puesto que la embriaguez no fue causa necesaria e infalible de la desgracia, ya que ningún "malvado" se embriagaba por excusar o cometer algún delito (Hidalgo y Carpio, 1877: 210-211).

${ }^{16}$ Lafragua, Escuela de Medicina, Fondo Adquisición, 313-316. 
entendimiento de los organismos sociales, generando un diálogo entre la psiquiatría y la criminología. ${ }^{17}$ La materia de Medicina legal, de 1894, que después desapareció en el plan de 1895, incluía

nociones de anatomía descriptiva, nociones de fisiología en general, estudio de las funciones cerebrales en sus relaciones con la criminología, estudio de las funciones del aparato génito-urinario, rudimentos de patología, nociones de obstetricia, cuestiones de matrimonio, antropometría, enfermedades simuladas y disimuladas, enfermedades que exceptúan el servicio militar, la enajenación mental, ${ }^{18}$ cuestiones relativas a los cadáveres, las autopsias, las inhumaciones y exhumaciones, las lesiones, las asfixias y el envenenamiento que iban de la mano con la antropología criminal. ${ }^{19}$

Regresando al plan de estudios de medicina, éste se mantuvo sin modificaciones hasta 1902, cuando se formó una comisión para presentar las reformas sobre los programas de instrucción secundaria para las carreras de Leyes, Medicina, Farmacéutica, Ingeniería, Comercio, Telegrafía práctica y, en particular, para la de Partera. El programa de medicina se volvió a modificar entre 1905 y 1906 de una manera muy sencilla, sin hacer ninguna modificación en cuanto a las enfermedades mentales, y la estructura prácticamente se conservó hasta la primera década del siglo xx.

\section{Las fuentes consultadas}

Los estudiantes utilizaron fuentes que escogían los maestros para mantenerlos actualizados. Entre esos materiales destacó la Gaceta Médica de México, que llegaba mediante una suscripción y que, junto con el periódico El Estudio, generaron un diálogo con los descubrimientos, avances médicos y teorías propuestas por los médicos mexicanos. En cuanto a los libros de texto recomendados, se advierte una actualización en los autores que practicaban la medicina experimental europea. Mientras que en el plan de estudios de 1855 se recomendaba el texto de anatomía de Bayle y Hollard (1828), en el de 1882 se sugería el de H. Beanis; la fisiología en el de 1855 era apoyada por autores como Richerard (1802), Bichat (1807), Magendie (1828) y Chaussier (1820), para ser sustituidos por el de Morel y Duval (1875), que trata la

\footnotetext{
${ }^{17}$ Este tema ha sido ampliamente estudiado por los historiadores del porfiriato. Para el caso de Puebla, consultar Nydia Cruz (1995) sobre el gabinete de antropología criminal en la penitenciaría del Estado de Puebla.

${ }^{18}$ Que incluía los delirios no vesánicos, la embriaguez, el hipnotismo y a los menores de edad.

${ }^{19}$ Lafragua, Colegio del Estado, Programas de estudio, Fondo Adquisición, 313-316. Son de especial interés los temas explorados, en cuanto a la antropología criminal, que siguió la propuesta de César Lombroso, en los que se tomaban en cuenta conceptos como la clasificación de delincuentes, caracteres morfológicos, caracteres fisiológicos, caracteres psicofísicos, caracteres religiosos y morales, etiología del delito y aplicación de la antropología a algunas cuestiones del derecho penal.
} 
fisiología de los centros nerviosos y, finalmente, en obstetricia se sustituiría el texto de Capurón (1813) por el de Cazeaux que había sido reeditado varias veces desde 1820 hasta 1869.20

La mayoría de los autores consultados en las demás materias, en ambos planes, eran de origen europeo, en particular franceses, salvo el Compendio de Medicina Legal de Hidalgo y Carpio (1877), que fue uno de los médicos forenses mexicanos más respetados de su época y que fue precursor de los casos de medicina legal. En lo que se refiere a psiquiatría, a pesar de que todavía no se había iniciado con la cátedra en la década de 1880, las obras de doctores como Charcot (1882), Gaillard (1879), Bossieau (1870), Bourneville (1898), Bouchut (1866), Marcè (1858, 1862), Menville (1858) y Longet (1842) fueron adquiridas para la biblioteca en 1878, y referenciados, ya pasados los años revolucionarios, ${ }^{21}$ lo que nos lleva a reflexionar sobre un difusionismo en cuanto a la influencia teórica.

En las tesis que aquí analizamos, las influencias más evidentes resultan las francesas, con trabajos como los de Charcot, Pinel y Esquirol.22 En algunos casos, los estudiantes referenciaron algunos casos de la Pitié-Salpêtrière, ${ }^{23}$ y de varios hospitales en los que dichas eminencias hicieron sus observaciones clínicas, incluso mencionando en varios casos el famoso "tratamiento moral" de Pinel (1809), pero a su vez también haciendo referencia a hospitales locales, creando un diálogo entre lo observado y lo teórico.

Aquí quisiéramos detenernos un momento, ya que si buscamos una base en la que estos estudiantes encontraran un apoyo constante tanto en sus tesis, como en su práctica profesional futura, será en la nosografía de Etienne Esquirol y en la teoría de la degeneración de August Morel. Recordemos que las propuestas de Etienne Esquirol (probablemente uno de los discípulos más conocidos de Pinel) lograron marcar una gran propuesta en cuanto a la nosografía ${ }^{24}$ de las enfermedades mentales. Desde la década de 1810, constantemente colaboró en el Dictionnaire des sciences médicales, editado por Panckoucke, en el que definió las enfermedades psiquiátricas como el delirio, la demencia, la demonomanía, la erotomanía, la locura, el furor, el idiotismo, las alucinaciones, la manía, la monomanía, la melancomía y el suicidio.

20 Para un informe más detallado de las materias y de las fuentes de cada uno de los planes, véanse Cortés y Palacios (2012: 188-196), para el de 1855, y Cortés (2010: 369), para el de 1882.

${ }^{21}$ Lafragua. Escuela de Medicina, Sección 4, Caja 40, Exp. 5.

22 Quizás éstos sean los tres psiquiatras más famosos de Francia. Sus estudios se volvieron la base para todas las observaciones en cuanto a enfermedades mentales en Europa y América. Frida Gorbach (2013) tiene un trabajo muy interesante sobre el difusionismo en cuanto a las teorías psiquiátricas, en particular la histeria, y cómo estas ideas llegaron a México en el siglo XIX.

${ }^{23}$ Este hospital se construyó en el siglo XVII y tuvo como propósito albergar a pobres y vagabundos de París. Se dividió en tres secciones: los niños estaban en La Pitié; los hombres eran internados en la Bicétre, y las mujeres en La Salpêtrière. En el siglo XIX, este recinto fue el lugar de observación de los padres de la psiquiatría moderna, como Pinel y Charcot.

${ }^{24}$ La nosografía se entiende como la clasificación de las enfermedades. 
Justamente en lo que define como "locura" dividió a la enfermedad mental en cinco "géneros": lipemanía (melancolía de los antiguos), monomanía, manía, demencia e idiocia, que buscaba refinar la clasificación hecha por Pinel. ${ }^{25}$ Entre sus propuestas más interesantes está la diferenciación entre "ilusión" y "alucinación", en la que los convirtió en signos físicos para considerarlos como parte de la semiología psiquiátrica, en lugar de la nosográfica; y la definición de "monomanía" como un delirio limitado solamente a un objeto, con excitación y predominio de una pasión alegre o expansiva, la cual era únicamente reconocida por los psiquiatras por su complejidad (Huertas, 1999).

Por su parte, la teoría de la degeneración de Morel (1857) otorgaba a la herencia, combinada con agentes causales como el alcoholismo, la miseria y el clima, la explicación de los comportamientos de individuos molestos, peligrosos y extraños. Esta teoría, que fue retomada por Magnan y Legrain (1895) unos años después, argumentaba que las enfermedades mentales eran producidas por las tendencias degenerativas que se heredaban de generación en generación, agravando la enfermedad hasta llegar a la extinción de la raza. Con esto se creaba

un estado patológico del ser que, comparativamente a sus progenitores más inmediatos, es constitucionalmente inferior en su resistencia psicofísica y no reúne más que incompletamente las condiciones biológicas de la lucha hereditaria por la vida. Esta inferioridad que se traduce en estigmas permanentes, es esencialmente progresiva, salvo regeneración intercurrente; pero fuera de esta excepción aboca más o menos rápidamente en el aniquilamiento de la especie (Morel, 1860).

\section{Las tesis de psiquiatría del Colegio del Estado de Puebla}

Como lo ha señalado Frida Gorbach (2007: 2), las tesis de medicina en estos años presentaron ciertas particularidades que se ven también en las tesis poblanas. A través de estos estudios se nota una necesidad de reseñar todo lo que se había estudiado hasta ese momento de dichos temas, como si fuera una vía de actualización, en las que se citaba la historia completa del padecimiento, mezclando en muchas ocasiones autores y épocas de una manera anacrónica. Propone que había un nuevo entusiasmo por la profesión médica, en la que se importaban teorías de Europa con la promesa de un futuro prominente, pero, en donde, de igual manera, vemos citados trabajos de sus colegas en la Ciudad de México. No obstante, advertimos que también se reflejan los intereses de los estudiantes y que responden a necesidades locales,

\footnotetext{
${ }^{25}$ Aunque no es el propósito central de este trabajo, advertimos que ésta es la clasificación presente en los diagnósticos de los hospitales de dementes de Puebla, lo que nos habla de que tanto la nosografía de Esquirol como la teoría degeneracionista de Morel constantemente eran mezcladas por los médicos del hospital (Bojalil, 2013). De igual modo observamos que en los trabajos de tesis también se alude constantemente a estos términos, demostrándonos que manejaban esta terminología.
} 
los cuales que fueron temas que, conforme avanzó el porfiriato, se volvieron una preocupación social y gubernamental. Entendiendo estas características, decidimos separar las tesis de psiquiatría de Puebla en tres apartados: las referentes al alcoholismo, la histeria y la psiquiatría óptica, para hacer una correlación, posteriormente, con la práctica médica de estos galenos.

Las tesis sobre alcoholismo de 1879 a 1898

El alcoholismo fue una preocupación muy fuerte en el porfiriato, como lo han señalado Pablo Piccato (1995; 1997), Daniel Vicencio (2014), Ricardo Pérez Montfort (2016), entre otros. Ya fueran médicos, criminólogos, liberales, higienistas, católicos o protestantes, autores como Miguel Jiménez (1866), Manuel Pasalagua (1874), Sebastián Labastida (1879), Luis Ruiz (1891), Trinidad Sánchez (1896), Julio Guerrero (1901), Carlos (1904), Fernando Ponce (1911) y muchos más, lo relacionaban directamente con la criminalidad y con la degeneración de la raza, que llevaría a México a tener una población improductiva.

Basados en estos problemas, los estudiantes José Agustín Galindo (1897), Ernesto Espinosa (1885), José de Jesús Ortega (1885) e Isaac del Río (1898) tocaron este tema en sus tesis, en las que podemos darnos cuenta de que los estudiantes compartieron esta preocupación con sus contemporáneos en la capital, ${ }^{26}$ así como algunos métodos de investigación. Pese a que el reglamento de 1879 establecía que estos trabajos deberían de ser producto de observaciones tanto clínicas, como teóricas personales, aparte de la larga revisión de autores extranjeros, advertimos que hacen referencia a sus observaciones en el Hospital de San Pedro, en el de San Hipólito, o inclusive, sin importar que no las hubieran hecho ellos mismos, de la Salpêtrière para así tratar de legitimar sus observaciones.

De entrada, esto nos resulta interesante, ya que en la ciudad de Puebla existían dos nosocomios especializados en enfermedades mentales que constantemente albergaban a una población de alcohólicos. Los hospitales de San Roque y Santa Rosa recibieron, durante todo el porfiriato, al menos a $108^{27}$ alcohólicos, 99 hombres y nueve mujeres, y ninguno de ellos fue mencionado en las tesis sobre alcoholismo, incluyendo el nombre de los hospitales. Estos números no eran desconocidos al público, por ejemplo, se reportaba que en el hospital de Santa Rosa, dirigido por el práctico Alberto Carlos Moreno, ${ }^{28}$ había 127

${ }^{26}$ Por poner sólo algunos ejemplos, Jiménez (1866), Pasalagua (1874) y Labastida (1879).

${ }^{27}$ Estadística obtenida de las órdenes de ingreso de ambos hospitales entre 1877 y 1894 y 1901 a 1910. Los expedientes de los años faltantes no se han encontrado. Reconocemos que este número podría incrementar, ya que en la época se pensaba que algunas manías, la lipemanía y otras enfermedades podían ser provocadas por la herencia alcohólica, sin embargo, solamente contamos con archivos administrativos y no expedientes clínicos por lo que sería muy difícil de determinar. Archivo General del Estado de Puebla (en adelante AGEP), Beneficencia Pública, Hospitales de dementes, Asilados, expedientes 110-340 y 1994-2432.

${ }^{28}$ Además de trabajar en los hospitales de dementes, este médico también trabajo en el Hospital de San Pedro realizando labores médico-quirúrgicas, administrativas y docentes (Fajardo, 2002: 464). 
dementes que era un "número alarmante si consideramos que la mayoría lo son por alcoholismo", ${ }^{29}$ eso sin contar las detenciones por "embriaguez y escándalo" de las que se escuchaba constantemente. ${ }^{30}$ Además, existían estudios como los de Samuel Morales y Secundino Sosa (1888), en los que se describía el tipo de bebidas alcohólicas consumidas por los poblanos y sus efectos en la población. A esto se le atribuían una gran cantidad de vidas perdidas y desgracias irreparables. Según estos autores, estaba probado, desde tiempo atrás, que la alimentación insuficiente generaba la necesidad de alcohol, que se catalogaba como "alimento de ahorro", por lo que llevaba al pueblo al abuso de bebidas como el pulque (p. 43). Tanto la ciencia, como la sociedad, estaban conscientes de que el alcoholismo producía enfermedades mentales y que afectaba directamente a la familia, como lo mencionaba un diario católico que publicó las consecuencias del consumo de alcohol según la teoría de Morel: "Primera generación: depravación moral, excesos alcohólicos. Segunda generación: embriaguez habitual, accesos de manía, reblandecimiento cerebral. Tercera generación: hipocondría, melancolía, suicidio. Cuarta generación: imbecilidad, idiotismo, esterilidad, extinción de la familia. ${ }^{31}$

Quizás la ausencia de referencia a los nosocomios poblanos se deba a su accesibilidad, intereses personales, tiempo o motivos laborales, como el caso de José Agustín Galindo ${ }^{32}$ (1879). Después de diez años de haber comenzado sus estudios, logró el tan ansiado título con el trabajo "Apuntes sobre el alcoholismo, en el que, basado en sus observaciones en la sala de Clínica Interna del Hospital General del Estado, en la estadística de defunciones de la capital de 1877 y en siete autopsias, estableció una correlación entre la predisposición individual y la afectación orgánica producida por el abuso en las bebidas "espirituosas", llevando a un alcoholismo agudo o crónico. La falta de alimento, la vida sedentaria, el temperamento linfático, la excitabilidad nerviosa y el uso de bebidas como el café creaban una situación muy grave que, sumada a las condiciones de edad y sexo particularmente en los hombres, eran consideradas como motivos de alteración profunda de los tejidos de órganos como los intestinos delgado y grueso, el páncreas, el hígado, riñones, arterias y aparato circulatorio.

Más que hacer una relación con autores extranjeros para tratar de sustentar sus observaciones, este estudiante, o quizás podríamos llamarlo "protomédico", se centró en hacer largas descripciones de sus observaciones clínicas en el Hospital General y los efectos que tenía esta sustancia en cada uno de los tejidos del cuerpo y, sobre todo, en las facultades

${ }^{29}$ El amigo de la verdad, 23 de marzo de 1884, p. 2.

${ }^{30}$ El Periódico Oficial del Gobierno del Estado de Puebla publicaba cada mes las multas cobradas por los diferentes delitos menores, como escándalo y embriaguez.

31 El amigo de la verdad, $1^{\circ}$ agosto 1891, p. 4, fragmento tomado de La revista de las Vegas.

32 Este estudiante no debe confundirse con el famoso doctor Agustín Galindo, que murió en 1885, quien fue muy importante para la Escuela de Medicina, para los hospitales General y Militar, así como regidor del Ayuntamiento (Robles, 2012: 404). 
intelectuales. Según él, en el hospital, estos enfermos tenían un "estado de indiferencia, mirada estúpida, voz ronca y temblorosa, movimientos lentos y perezosos con falta de coordinación y color de piel pálida", conduciéndolos al delirium tremens y a la locura lipemaniaca.

Más allá de eso, su expediente es muy interesante, ya que presentó dos solicitudes de inscripción, una en 1869 y otra en 1874. No sabemos a qué se debió; aun así, inferimos que, después de la reapertura de la escuela, al finalizar la clausura ordenada por el emperador Maximiliano de Habsburgo entre 1863 y 1867, la situación administrativa haya sido muy desordenada. Junto con las dos solicitudes de inscripción, hay dos solicitudes de examen final: una de 1875, que venía acompañada de un documento que certificaba que había pasado las materias de manera sobresaliente, y otra de 1879, en que se mencionaba que exclusivamente le faltaba el examen de toxicología para reunir los requisitos de examen final. En el expediente de este alumno, lo más interesante es que el 30 de enero de 1880 se mandó un oficio en el que se expuso que, según la Ley de 1878, el alumno no había cursado todas las materias, ya que había ingresado cuando el plan de 1856 estaba vigente, pero que su caso sería revisado. Al final de estos trámites, pudo hacer su examen del 11 al 13 de marzo de 1880 , y no en 1879 como dice su tesis. ${ }^{33}$

No sabemos qué haya hecho en esos años intermedios, sin embargo, destacó por tener una vida académica muy activa, lo que lo llevó a trabajar en el Hospital de San Pedro (Fajardo, 2002: 465); a ser catedrático de la Escuela de Medicina; segundo vocal del Consejo Superior de Salubridad y parte de la Sociedad Médica de Beneficencia de Puebla (Robles, 2012: 400); médico de los hospitales de dementes, en sustitución de Rafael Serrano en 1920;34 y a ser responsable de la asistencia médico-quirúrgica de la Beneficencia Española de Puebla, en 1923, junto con el doctor Isaac del Río.35

Seis años más tarde, Ernesto Espinosa ${ }^{36}$ (1885) y José de Jesús Ortega ${ }^{37}$ (1885) retomaron el tema y lograron recibirse sólo unos meses antes de que el gobernador Márquez clausurara la Escuela de Medicina. Espinosa, desde la perspectiva legal, se concentró en la responsabilidad criminal en caso de encontrarse en estado de embriaguez. Citó a autores como el doctor Mata (1864), a Legrand (1874) y a Hidalgo y Carpio (1877), al referirse al poder que tenía el hombre, por medio de la reflexión y sus auxiliares, en la realización de sus

${ }^{33}$ Lafragua, Escuela de Medicina, Estudiantes, caja l, exp.39.

${ }^{34}$ AGEP, Beneficencia Pública, Hospitales de dementes, Fondo 05, Secc. 1, Exp.114, Caja 49.

35 Sociedad Española de Beneficencia de Puebla (1923)

${ }^{36}$ Ernesto Espinosa ingresó a la Escuela de Medicina en 1881, después de haber comprobado que había cursado todas las cátedras de la educación preparatoria. Después de cuatro años, solicitó fecha de examen profesional el 26 de septiembre de 1885, que le fue concedido del 5-7 de octubre de ese año. Lafragua, Escuela de Medicina, Estudiantes, Caja 5, Exp.48.

${ }^{37}$ Este expediente, con sólo una foja, es muy confuso, y en él se pide el ingreso en 1854, pero junto tiene una anotación que dice 1899, por lo que no sabemos exactamente a quién corresponde, si a él o quizás a su padre. Lafragua, Escuela de Medicina, Estudiantes, Caja 4, Exp.40. 
impulsos internos llegando a un arreglo en las leyes de la organización (p. 25). De manera desordenada, dando un carácter universal al alcoholismo, revisó los códigos penales de diferentes épocas y lugares, como Grecia, Roma, el Derecho canónico, las cortes de Carlos V y Francisco I, las leyes árabes y musulmanas, las legislaciones de Inglaterra, Francia, Austria, Italia, Portugal, España, las de Texcoco, las del virreinato y las leyes emitidas desde la Independencia hasta el porfiriato.

En su trabajo, describió casos prácticos a través de las semejanzas entre la embriaguez habitual y la dipsomanía, concluyendo que en los casos de delito bajo los influjos del alcohol la diferencia en la responsabilidad residía en el hábito de consumir o no bebidas espirituosas. Dio dos ejemplos, sin ninguna descripción o historia clínica, que ilustraban su punto, en el que reconocía que un individuo podía ejecutar actos punibles estando perdida la razón. El primer caso lo extrajo del libro de Legrand du Saulle, Medicina legal, en el que se relataba a un mensajero de Pedro el Grande, el cual, en estado de ebriedad, había violado a la zarina y fue perdonado. El segundo venía de la causa 121 del Juzgado $2^{\circ}$ de lo criminal, en la cual un soldado mató a su hijo y también fue exonerado por estar en estado de ebriedad.

Sabemos que, en México, y obviamente en Puebla, este tema era una gran preocupación. Tanto los intelectuales como la prensa señalaban que la mayor parte de los crímenes que se cometían se debían al poco celo que ponían los padres en la educación, pero también, en al abandono total por parte de las autoridades para evitar estos males.38 El artículo 34 del Código Penal de 1884 de Puebla, por ejemplo, colocaba como excluyente de la responsabilidad criminal a la embriaguez completa, que privaba enteramente de la razón, si no era habitual, ni si el acusado había cometido antes una infracción punible estando ebrio; el artículo 41, consideraba como atenuante de tercera clase a la embriaguez incompleta, si era accidental e involuntaria; mientras que el artículo 11 declaraba como culpable si se infringía una ley penal hallándose en estado de embriaguez completa, si tenía habito de embriagarse, o si había cometido anteriormente alguna infracción punible en este estado (Espinosa, 1885: 7). Para ilustrar esto, de acuerdo con sus escritos, estaban los cadáveres que muchas veces se sacaban de las pulquerías y cantinas, cuyos asesinos no recibían castigo al guno gracias a que estaban en estado de embriaguez. Por ejemplo, la prensa denunciaba casos como el asesinato de D. Antonio G., español de "muy buen corazón", a manos de otro alcohólico que le disparó en Chalchicomula y que quedó libre, ${ }^{39}$ o el caso de un hombre que mató a su hermano en estado de embriaguez y que nunca recibió castigo. ${ }^{40}$

\footnotetext{
${ }^{38}$ El amigo de la verdad, 15 de abril 1882, p. 3.

${ }^{39}$ El colaborador católico, 10 mayo 1885, p. 3.

${ }^{40}$ El colaborador católico, $1^{\circ}$ febrero 1885, p. 4.
} 
En los años posteriores a su graduación, el doctor Ernesto Espinosa ganó un muy buen reconocimiento como médico perito en los juicios de interdicción, ${ }^{41}$ atendiendo alrededor de cincuenta casos entre los años de 1893 a 1898, ${ }^{42}$ junto con su buen amigo y compañero de estudios Alberto O'Farril. ${ }^{43} \mathrm{~A}$ la par, escribió constantemente en el periódico El Demócrata, ${ }^{44}$ que fue clausurado por el gobierno del general Díaz por no apegarse a la línea oficial. Su fama y fortuna lo llevaron a abrir el gran Teatro Variedades, que se volvió todo un exponente de la ópera y de la cinematografía en la ciudad. ${ }^{45}$

Regresando a las tesis de psiquiatría, los objetivos de José de Jesús Ortega (1885) se enfocaron en el estudio del alcoholismo en general, sobre el alcoholismo del pulque, los fenómenos químicos fisiológicos, el alcoholismo agudo y el crónico y, finalmente, la influencia que tenía en la sociedad. Como en los otros casos, llama la atención la falta de especificidad en sus observaciones, ya que, los casos particulares que menciona, carecen de referentes, como si todo el que leyera su tesis tuviera la obligación de conocerlos. La mayor parte de su trabajo se enfocó en describir, de manera teórica y sin autores referenciados, los efectos del alcohol en los órganos del cuerpo y en hablar sobre su historia, pero al referirse a pacientes, sólo menciona a uno con delirium tremens y a otro que "quedó idiota", sin darnos más detalles.

Sus conclusiones en cuanto a la educación de las clases menesterosas son atrayentes, ya que atribuía la manera de ser moral del individuo a la impresión psíquico-moral que recibía el óvulo desde la fecundación, por lo que era indispensable germinar en él la facultad de neutralizar las malas impresiones (Ortega, 1885: 37). Resultado de esto, el delincuente alcohólico dejaba de ser responsable por sus acciones por la falta de educación y por la exaltación que provocaban estas bebidas, que lo hacían olvidar la condición social a la que estaba obligado por necesidad.

Este debate, que confrontaba a la ciencia y la religión, era muy común en el siglo XIX. Si la ciencia lo colocaba en la impresión psíquica moral heredada, la religión lo atribuía a la carencia de enseñanza de la moral en las escuelas, otra vez demostrándonos que existía un constante diálogo entre las corrientes extranjeras y los problemas y soluciones locales. En lo

${ }^{41}$ El juicio de interdicción era un recurso legal para proteger a los mayores de edad que, por su padecimiento, perdían la capacidad de manejarse por sí mismos. En él se nombraba un tutor, que representaría al enfermo mental, y un curador, que se encargaba de vigilar que las acciones del tutor fueran en beneficio de su representado.

${ }^{42}$ Todos estos casos se encuentran registrados con diferentes fechas en el Periódico Oficial del Cobierno del Estado de Puebla.

${ }^{43}$ A pesar de que este médico no realizó una tesis sobre psiquiatría, sus intereses lo llevaron a abrir el Instituto Kéeley, en la calle de Aztecas, en 1908, en el que se curaba "el alcoholismo, la neurastenia, el hábito del tabaco, opio, cloral, morfina, cocaína y demás drogas" (Mendizábal, 2009: 167). Igualmente, fue catedrático de anatomía descriptiva y perito en los juicios de interdicción, como se dijo antes, con Ernesto Espinosa, volviéndose una autoridad en este tema en la ciudad.

${ }^{44}$ Periódico Oficial del Gobierno del Estado de Puebla, 8 de noviembre de 1885, p. 219.

${ }^{45}$ Cabe mencionar que el doctor Espinosa fue padre del famoso Manuel Espinosa Iglesias que, al heredar la fortuna de su padre, se convirtió en uno de los más grandes empresarios de Puebla en el siglo XX. 
que sí coincidían era en que las clases menesterosas debían ser objeto de una atención especial de quien correspondía, y de la compasión de sus desgracias de la clase culta. De ello se desprendía que si esa clase abusaba de las bebidas alcohólicas era porque, de la mano con la excitación que producían, estaba obligado por la necesidad.

Sin embargo, la crítica más fuerte siempre venía de parte de los grupos católicos que reclamaban que las autoridades deberían procurar la integridad en la juventud a través de escuelas en las que verdaderamente se enseñara la moral, basadas en la religión, para poner remedio a los muchos males que existían. ${ }^{46}$ Recordemos que las Leyes de Reforma, aparte de los establecimientos de beneficencia, pusieron en manos del Estado la educación, por lo que el desarrollo moral del individuo se había transformado de una moral católica a la liberal, que, según la prensa católica, se confundía con el "libertinaje". Por consiguiente, en el Reglamento para las escuelas primarias elementales del Estado de Puebla (de 1893) estaban ausentes todo tipo de conceptos morales para ser sustituidos por los higiénicos, lo que, según la Iglesia, era la causa del incremento en la peligrosidad de la población.

Trece años pasaron para que un estudiante volviera a observar el alcoholismo. La tesis de Isaac del Río ${ }^{47}$ (1898) lo consideraba un veneno que afectaba no sólo al cuerpo, sino a la sociedad. Igual que sus compañeros, mezcló indistintamente a autores, sin mencionar a cuál de sus obras se refería. Así, citó a médicos como Bins, Heubach y Schmidt, ${ }^{48}$ Dujardin, ${ }^{49}$ Dujardin-Beaumetz, ${ }^{50}$ Manquat,, ${ }^{51}$ Bernard, ${ }^{52}$ y Magnan ${ }^{53}$ para hablar de las lesiones que causa el alcohol al cuerpo, y utilizando, al mismo tiempo, algunas estadísticas del Hospital de San Hipólito y la Salpêtrière de París, para ejemplificar los casos, pero nunca dando historias clínicas específicas. Su conclusión, aparte de demostrarnos este constante diálogo entre las teorías francesas y las necesidades locales, radicaba en que la familia era afectada por este hábito, haciendo repugnantes las relaciones sexuales y, por ende, la reproducción de

${ }^{46}$ El amigo de la verdad, 15 de abril 1882, p. 1.

${ }^{47}$ No se encontró el expediente de este alumno, por lo que no podemos proporcionar más datos sobre él.

${ }^{48}$ Según este estudiante, estos autores habían encontrado en sus trabajos que sólo cuando se toma una cantidad considerable de alcohol se presenta el aldehído en la orina en una proporción del 4 por ciento, pero cuando se ingiere en pequeñas cantidades no se encuentra nada.

49 Podría estar citando cualquiera de sus obras (Dujardin, 1831, 1841, 1843).

50 Hemos encontrado varias obras de este autor (1879-1883, 1887, 1893, 1894), y en coautoría con Charles Debierre, Charles, Bardet y Godefroy (1883-1895).

${ }^{51}$ Menciona de este autor que no se puede admitir que el alcohol, tan ávido de oxígeno y hemoglobina siempre dispuesta a cederlo, se pongan en contacto sin que se verifique alguna reacción. A lo mejor cita su trabajo de 1898.

${ }^{52}$ Cita a Claude Bernard, diciendo que puede ser un veneno, puesto que no puede entrar a formar parte de la composición de la sangre ni penetrar en el organismo sin causar desórdenes más o menos pasajeros o permanentes. Este médico francés fue un biólogo teórico, médico y fisiólogo, fundador de la medicina experimental. Son muchas y muy conocidas sus obras, pero quizás podría estar citando sus trabajos de 1858a y 1858b.

${ }^{53}$ De la obra de Valentín Magnan menciona que había demostrado en sus experimentos con animales y sus estudios clínicos en el hombre, que lo que se había considerado como epilepsia alcohólica no era más que un temblor muy intenso, acompañado algunas veces de convulsiones clónicas. Podría estar remitiendo a Magnan (1871; 1873; 1874). 
la sociedad; volvía impotente y adúltero al hombre; y los disgustos domésticos frecuentes, resultando muchas veces en heridas y golpes. El borracho, según este estudiante, llevaba a la desmoralización de la familia, transmitiendo esta herencia a sus hijos, que ya predispuestos, seguían el camino de su padre condenando a la familia a la desgracia, la miseria y, tal vez, a la prostitución y el crimen (Del Río, 1898: 37), como bien lo diría la teoría de la degeneración de Morel y que poco a poco fue permeando en la población y en los círculos académicos.

La violencia intrafamiliar era uno de los grandes problemas que preocupaban a los diferentes grupos, ya fueran religiosos o gubernamentales. Las mujeres, sin importar su edad, condición social o si estaban embarazadas, eran golpeadas por sus maridos, e incluso se contagiaban de enfermedades venéreas (Morales y Sosa, 1888: 16). Esto lo convertía en una peligrosa plaga que no enfermaba sólo al que la padecía, sino a sus descendientes, por lo que, en el siglo XIX, se pensaba que el alcohólico no sólo conspiraba contra sí mismo, sino contra los demás.

Uno de los principales objetivos del régimen de Porfirio Díaz fue fomentar y garantizar el bienestar de la población mexicana. Mediante reglamentos y campañas, se trataba de concientizarla de los grandes problemas de salud, por lo que primero era necesario saber cuál era el verdadero alcance de la enfermedad. Por lo tanto, la estadística y los estudios científicos se volvieron preponderantes para entender las causas de los problemas y crear medidas para erradicarlos. De esta manera, se realizaron campañas de vacunación, se creó un código sanitario y se expidieron reglamentos para el comportamiento de la población. Aunque su efectividad dejó mucho qué desear, se buscaba erradicar estas costumbres para crear individuos calificados en una colectividad que tuviera todas las condiciones higiénicas para el progreso, que serían resultado del esfuerzo conjunto entre médicos, higienistas, maestros e ingenieros sanitarios.

Asimismo, el alcoholismo estaba asociado a otras enfermedades, como el sarampión, la tifo, la viruela, la escarlatina y la cirrosis (Ponce, 1911: 22). Producto de esto, los altos contrastes llevaron a buscar una solución: limpiar las calles, establecer drenajes, abastecer de agua potable, pero, sobre todo, intentar cambiar las costumbres de la sociedad.

\section{La tesis de psiquiatría óptica de Rafael Serrano de 1884}

Si quisiéramos hablar de los psiquiatras poblanos más famosos de la época, tendríamos dos nombres: Rafael Serrano y Secundino Sosa. ${ }^{54}$ Aunque sabemos que Sosa se inscribió en 1876

\footnotetext{
${ }^{54}$ Secundino Sosa fue parte del círculo católico poblano; escribió artículos sobre el alcoholismo y la epilepsia en la Gaceta Médica de México; fue miembro del periódico médico-farmacéutico El Estudio, en 1875; realizó experimentos con epilépticos, en el Hospital del Divino Salvador, y fue uno de los fundadores del Instituto Médico Nacional; fue secretario de la Sociedad Médica de Beneficencia, de Puebla en 1883; y fue catedrático, al igual que Serrano, en la Escuela de Medicina de Puebla (Robles, 2012: 400-422). Además, realizó un estudio con Samuel Morales (1888).
} 
en la Escuela de Medicina del Estado, ${ }^{55}$ terminó sus estudios en la Escuela Nacional de Medicina, pero quizás haya compartido una visión común en cuanto a las enfermedades mentales con Rafael Serrano, ya que ambos fueron médicos de los hospitales de dementes: Sosa en el Divino Salvador, de México, y Serrano en los de San Roque y Santa Rosa, de Puebla.

En lo que compete a Rafael Serrano, ${ }^{56}$ logró convertirse en un psiquiatra muy reconocido. Su fama y compasión fue tal que se creó un "Pabellón Rafael Serrano" en el Hospital General a principios de siglo XX, y varios años después, el psiquiátrico que hasta la fecha sigue funcionando en el estado de Puebla lleva su nombre. Una vez concluidos sus estudios profesionales, ingresó inmediatamente como médico y administrador de los hospitales de dementes, ocupando la plaza entre los años 1885 y 1895 y de 1909 hasta 1915.57 Conjuntamente, fue director del Hospital Guadalupe para dementes en Cholula, en 1910; fue catedrático de la Escuela de Medicina; miembro honorario de la Sociedad Médica de Beneficencia de Puebla; director de la Escuela Normal y del Colegio del Estado, asimismo asistió a varios congresos científicos médicos nacionales e internacionales, todo eso sin contar sus funciones como médico perito en juicios de interdicción (Cruz, 1995: 452).

Su tesis, intitulada "Fragmentos de psiquiatría óptica", partió de "la relación entre la luz y la fuerza nerviosa considerada desde el punto de vista psíquico, para demostrar que las leyes fundamentales de la óptica aplicadas al sistema nervioso explican en gran parte la patogenia de la enagenación [sic] mental" (Serrano, 1884: 2). Esta investigación, premiada en 1890 por la Academia Nacional de Medicina, se recomendó a nivel nacional como indispensable para entender el manejo de las leyes ópticas en los ámbitos de las ciencias biológicas.

Representó una innovación en la materia, ya que proponía que las relaciones anatómicas y funcionales entre la corteza del cerebro y la retina llegarían a establecer en el oftalmoscopio ${ }^{58}$ una de las bases del diagnóstico de la enajenación mental y harían de la cerebroscopía de Bouchut (1880) uno de los más importantes auxiliares de la psiquiatría Serrano, 1884: 1). A lo largo de todo el trabajo citó a diferentes autores franceses, alemanes y españoles, ${ }^{59}$ para

${ }^{55}$ Lafragua, Escuela de Medicina, Estudiantes, Caja 3, Exp. 12.

${ }^{56}$ Rafael Serrano solicitó la inscripción a la carrera el 30 de diciembre de 1879, no obstante, le fue condicionada porque no pudo comprobar sus estudios preparatorios. Seguramente tuvo que haber cumplido con el requisito porque realizó la solicitud de examen final el 4 de enero de 1884, el cual le concedieron en julio de ese año para realizarse los días 22, 23 y 29 de diciembre. Sus sinodales fueron los Doctores José María Calderón, Secundino Sosa, Carlos Briseo y Manuel Toussaint, todos catedráticos de la Escuela de Medicina. Lafragua, Escuela de Medicina, Estudiantes, Caja 3 , Exp.3. En este punto hay que resaltar que el único de estos médicos que trabajó enfermedades mentales fue Secundino Sosa (1901).

${ }^{57}$ ACEP, Beneficencia Pública, Hospitales de dementes, Fondo 05, Secc. 1, Exp.114, Caja 49.

58 Instrumento para ver ampliado el fondo del ojo, en donde se encuentra la retina.

59 Para hablar de la neuralidad citó a Vulpian (1866); de Newton (1779) retomó la problemática sobre si los rayos luminosos al excitar la retina originan vibraciones que, transmitidas por el nervio óptico, producían en el cerebro el sentido de la vista; de Echegaray (1873) tomó teorías físicas; de Briot (1842) utilizó la teoría de la luminosidad; en cuanto a psicología se basó en el libro de Ribot (1875); la unidad de estructura y de función del sistema nervioso lo 
hablar de la influencia que tenían los agentes físicos en la etiología y en el tratamiento, así como los recursos que se podían prestar para el diagnóstico de las frenopatías (o enfermedades mentales). Cabe resaltar que el estudio de Serrano se basó en casos clínicos observados en los hospitales de dementes de San Roque y de Santa Rosa, siendo el único alumno que recurrió a estos nosocomios para realizar investigación, demostrándonos de nuevo que sí era posible un diálogo entre las propuestas internacionales y las necesidades locales. En la segunda mitad del siglo XIX, las propuestas en materia de psiquiatría provenían de una herencia que había comenzado desde principios de siglo y que se continuaba reconociendo su importancia. Tal es el caso de los médicos que trabajaban en los laboratorios experimentales y en los hospitales de dementes europeos, como Pinel, Charcot y Esquirol, que trabajaron en la Salpêtrière.

A diferencia de sus compañeros, Serrano fue el único estudiante en realizar un trabajo muy detallado en todos los sentidos. Las referencias bibliográficas se encuentran perfectamente incluidas en el texto y, lo que es mejor, las historias clínicas también. En éstas, al igual que Pinel y Esquirol, incluyó el estatus social, la familia de los enfermos, la descripción de los síntomas de la enfermedad, así como la degeneración de las facultades mentales y, en caso de existir, la autopsia. Así mismo, incluyó textualmente historias clínicas de otros autores sin perder ningún detalle, citando por ejemplo casos de Esquirol (1854) y Despine (1875) que se convirtieron en la base de sus conclusiones.

Además, en su trabajo hizo una correlación sistemática entre las leyes de la física-óptica con la medicina para establecer la relación entre la vista y la forma anatómica y funcional del cerebro. Su metodología se enfocó en describir la etiología de las psicosis, ${ }^{60}$ mediante el estudio de caso, el análisis del origen de la enfermedad, su diagnóstico, la observación evolutiva, tanto en el hospital como en el exterior, así como el tratamiento de acuerdo con el estado en el que se encontraba la enfermedad.

Según Rosario Robles (2004), en esos años era imperante lograr un trabajo conjunto entre las ciencias racionales y las exactas, mediante los principios de la medicina y la psicología. Por tal motivo - remarca la autora - Serrano combinó la anatomía patológica, que indicaba el lugar en el que estaban las lesiones cerebrales, con el uso de la celda de fuerza o recinto oscuro, utilizado en Francia y España, para ayudar a los pacientes con accesos de furor, delirium tremens, manía aguda, periencefalitis difusa, locura impulsiva y locura sensorial, lo que en su momento resultó un gran adelanto.

tomó de Lewes (1875), y de Richet (1882) mencionó la Ley de la vibración ondulatoria aplicada a la fisiología del sistema nervioso.

${ }^{60}$ La psicosis es una enfermedad que se caracteriza por la alteración global de la personalidad a través del trastorno del sentido de la realidad. 
Si bien se le relacionó también con el género masculino (Pérez, 2016) la histeria fue una enfermedad que se creía que principalmente atacaba a las mujeres (Foucault, 2005; DidiHüberman, 2007; Huertas, 2014; Libbrecht, 1995; Briggs, 2000; Morantz y Zschoche, 1980; Freedman, 1982; Micale, 1993; Agostoni, 2002; Gorbach y Train, 2005; Gorbach, 2007; 2008; 2013).

No obstante, como lo ha planteado Frida Gorbach (2007: 3), en México, la histeria se concibió como una enfermedad fisiológica ${ }^{61}$ que dejaba atrás la centralidad del útero y se explicaba gracias a la fragilidad y sensibilidad de las mujeres, y que era producto de la modernidad. ${ }^{62}$ Así pues, médicos y estudiantes trataron de definirla como un resultado de la vida ociosa de las mujeres (Olvera, 1870: 5); que afectaba a las clases altas más que a las bajas (Mejía, 1878: 476), y que resultaba del egoísmo extremo en el que vivían (Mejía, 1896: 463). Como lo ha señalado Gorbach (2007: 8), "si la histeria se debía a una exacerbación del yo, y la exacerbación del yo constituía una patología inherente a la modernidad, entonces ¿qué hacer con esa enfermedad?, ¿resignarse a padecerla o detener su proliferación?”. Así tenemos varios casos reportados en Puebla, a través de los juicios de interdicción, como el de Carmen M., de 1888,63 el de María L., de 1902:64 Adela H.; de 1900;65 Francisca A., de 1898:66 Emilia G., de 1887; ;7 y Francisca T., de $1896^{68}$ que nos hablan de la preocupación de las familias por estas mujeres que presentaban un comportamiento errático, desaliñado y totalmente fuera de lo común.

En este universo de propuestas, la tesis de Francisco Rodiles ${ }^{69}$ (1885), "Breves apuntes sobre la histeria, seguidos de un apéndice sobre locura histérica", se sumó a las de sus contemporáneos, reconociendo una enfermedad que se caracterizaba por una multitud

${ }^{61}$ La fisiología es una parte de la biología que estudia los organismos de los seres vivos y su funcionamiento.

${ }^{62}$ Fueron muchos los médicos que la estudiaron, por ejemplo, Charcot (1882), Grasset (1889), Colin (1890), Bernheim (1913), Briquet (1859), Falret (1890), Lasègue (1873), Gilles de la Tourette (1891), Breuer y Freud (18931895) y Kraepelin (1901).

${ }^{63}$ AGEP, Beneficencia Pública, Hospitales de dementes, Asilados, exp. 212.

${ }^{64}$ Periódico Oficial del Gobierno del Estado de Puebla, 26 de agosto de 1902, p. 202.

${ }^{65}$ Periódico Oficial del Gobierno del Estado de Puebla, 9 de enero de 1900, p. 24.

${ }_{66}$ Periódico Oficial del Gobierno del Estado de Puebla, 29 de noviembre de 1898, p. 460.

${ }^{67}$ Periódico Oficial del Gobierno del Estado de Puebla, 10 de marzo de 1887, p. 359.

68 Periódico Oficial del Gobierno del Estado de Puebla, 25 de agosto de 1896, p. 222.

${ }^{69}$ No sabemos exactamente en qué año ingresó a la Escuela de Medicina, pero tuvo que haber sido en 1880, ya que existe un oficio del 19 de octubre, de ese año, en el que presentó el examen de Anatomía descriptiva que pertenecía a las materias de primer año. A lo largo de su expediente observamos las fechas y votos aprobatorios de los diferentes exámenes, que podían ser por unanimidad o por mayoría. De la misma manera, presentó varias solicitudes de exámenes extraordinarios y a título de suficiencia por no haber podido hacerlos, ya que tuvo que salir de la ciudad, los cuales fueron autorizados por el Secretario de Fomento. Por último, el acta del 11 de abril le autorizó el examen final que se llevaría a cabo los días 15 a 17 de ese mes, siendo, según este documento, sus sinodales los doctores Guillermo 
y variedad de fenómenos tan grande, que podía confundirse con cualquier otra, como la hipocondría o el estado nervioso. Examinó causas predisponentes y ocasionales físicas, como la anemia, la cloroanemia, la menorrea y la dismenorrea, o la vida sedentaria, la herencia y la miseria o la continencia, los excesos de coito y el onanismo; y las psíquicasmorales, como la lectura de ciertos libros, conversaciones deshonestas, la vista de cuadros o estampas impúdicas, ciertos espectáculos teatrales, acontecimientos desgraciados, espectáculos tristes, pasiones contrariadas y el amor excesivo a las bellas artes como la pintura y la música (Rodiles, 1885: 10). Citó, asimismo, a autores clásicos como Hipócrates y Galeno hasta modernos como Willis (1667), ${ }^{70}$ Sidenham (1676) ${ }^{71}$ y Briquet (1859) cuando explicó el cambio de concepción que llevó a pensar que la histeria se generaba en el sistema nervioso y no en el útero, como lo pensaban los griegos.

Para Rodiles era indispensable procurar que los sujetos se encontraran siempre ocupados ${ }^{72}$ alternando las ocupaciones con pareos y ejercicios gimnásticos. En el caso de ya sufrir la enfermedad, recomendaba el uso de antiespasmódicos, por ejemplo, el éter por vía gastrointestinal, o pulmonar, por inhalaciones; el cloroformo, la valeriana, el castóreo, la asafétida, el óxido; el sulfato de zinc, el alcanfor; los narcóticos, como el opio y sus derivados; el estramonio y la belladona. Hizo referencia a un artículo de la Gaceta Médica de México en la que se recomendó el bromuro de potasio o las píldoras antihistéricas de Debreyne, que contenían alcanfor, asafétida, extracto de belladona, extracto de opio y jarabe de goma y, en casos extremos, se exhortaba al matrimonio con un hombre vigoroso, o la hidroterapia (Rodiles, 1885: 53), lo que nos habla de una constante búsqueda de propuestas entre los autores internacionales y las publicaciones mexicanas. No sabemos más de este estudiante, pero suponemos que quizás haya podido ejercer su profesión en la Ciudad de México.

\section{Conclusiones}

Como lo planteamos desde las primeras páginas, se ha tendido a separar el "difusionismo" de la "historia nacional de la ciencia en México" como si fueran dos corrientes totalmente excluyentes, como si ninguna pudiera tomar en cuenta a la otra para su configuración (Gorbach, 2013). Sin embargo, a lo largo de estas páginas hemos observado que los estudiantes de medicina enfocados en temas relacionados con las enfermedades mentales durante el porfiriato

Dávila, Francisco Bello, Leonardo Córdova y Juan Calderón, reconocidos médicos y maestros de la institución. Lafragua, Escuela de Medicina, Estudiantes, Caja 1, Exp.59.

70 Thomas Willis (1621-1675) estudió la histeria y la hipocondría.

${ }^{71}$ Thomas Sydenham (1624-1689) fue un médico inglés que proponía una nueva patología basada en la descripción de las enfermedades.

${ }^{72}$ Reconoce que esta enfermedad también se presentaba en los hombres. 
en Puebla recibieron una fuerte influencia de autores extranjeros, pero al mismo tiempo trataron de buscar una solución a los problemas locales, creando una interacción entre ambas visiones.

Por ejemplo, cuando hablamos de alcoholismo, tanto liberales como católicos y protestantes se quejaban constantemente de los efectos del abuso de bebidas espirituosas en la población, que llevaban a situaciones como la ausencia laboral -el "San Lunes"-, el mal ejemplo que recibían los niños de sus padres al verlos borrachos, la promiscuidad y la vagancia, la violencia intrafamiliar, el gasto excesivo en bebidas que mermaba la economía familiar, el alcoholismo a una edad temprana, las riñas en las cantinas y pulquerías, así como la prostitución y el juego (Bojalil, 2018b). O si hablamos de la histeria, como lo menciona Gorbach (2007), se trataba de buscar una solución a la condición ociosa de la mujer en la modernidad, que la llevaba a tener estos ataques repentinos, que podían ser confundidos con cualquier otra enfermedad. Gracias a estos temas, los estudiantes de medicina intentaron dar, antes que nada, una explicación a la enfermedad, basados en las definiciones europeas, pero al mismo tiempo una reflexión, sobre todo a las condiciones de la población que hacían que se reprodujeran estas prácticas. Así, leemos en sus estudios que hablan de clases sociales, de género, edad y educación para tratar de establecer una división categórica de la sociedad y sus problemas, e incluso plantean soluciones económicas y sociales, como el incremento a los salarios de los jornaleros, así como un cambio en la educación de los niños, para el caso del alcoholismo; o la prevención de la ociosidad, el onanismo, las impresiones fuertes o la excitación para las mujeres histéricas, es decir, a las mujeres modernas que solamente se quedaban en casa sin tener alguna actividad.

Más adelante, en su práctica profesional, seguirán buscando una solución a estos problemas al convertirse en médicos especializados en dichos temas, al trabajar en los hospitales de dementes, al ser catedráticos o en su práctica privada. Además, también notamos que muchos de ellos se convertirán en un referente en la sociedad y en la medicina, como Rafael Serrano, y serán invitados a participar en congresos nacionales e internacionales.

A pesar de la atracción por los problemas locales, advertimos que existe una total confianza en las aportaciones teóricas de los médicos extranjeros, como si desde Aristóteles a Galeno y de Pinel a Morel, pasando por todos los demás periodos históricos, todo lo que se hubiera dicho fuera absolutamente verdadero, como si no existiera una evolución en el concepto de enfermedad y como si no pudiera cuestionarse. Como lo ha mencionado Gorbach, podría parecer que la definición de estas enfermedades se implantaran en un campo vacío a simple vista, sin embargo, vemos que la diferencia con los galenos franceses será que toman en cuenta las características que consideran totalmente únicas de la población mexicana, como la raza, la educación, la cultura precolombina, la influencia colonial y el sincretismo cultural. A excepción de Francisco Rodiles, que reconoce que la teoría uterina ya no es aceptada para 
explicar la histeria, los demás tesistas nunca cuestionaron a los grandes maestros ni sus grandes obras. Claro que entendemos que el concepto de tiempo no era el centro de atención en sus estudios, sino, más bien, la enfermedad misma, la novedad, como lo cuestiona Gorbach (2007) en su trabajo sobre la histeria y la monstruosidad, y esta "voracidad" de estudiar lo que no se había estudiado en México.

Tomando todo esto en cuenta, argumentamos que, más allá de buscar una explicación a los problemas locales, únicamente desde la influencia francesa, inglesa o estadounidense, o desde un punto de vista exclusivamente local, estos estudiantes parecerían brincar de un punto de vista a otro, tratando de comprobar lo que decían los grandes autores, pero al mismo tiempo tratando de hacer alguna aportación nueva a los conceptos, con base en las características propias de su sociedad. El empirismo fue su mejor herramienta, a través de las autopsias de cadáveres, en las que se describe con extremo detalle y se trataba de dar a la enfermedad no solamente un sustento teórico, sino también práctico, en una población específica: el enfermo mental poblano.

\section{Fuentes}

Archivos

AGEP Archivo General del Estado de Puebla, Puebla.

Lafragua Biblioteca Histórica José María Lafragua, Benemérita Universidad Autónoma de Puebla.

\section{Hemerografía}

El amigo de la verdad. Periódico Religioso y Social dedicado a la instrucción del pueblo, Puebla

El colaborador católico, Periódico semanario. Chalchicomula, Puebla.

Periódico Oficial del Gobierno del Estado de Puebla.

\section{Bibliografía}

Agostoni, Claudia (2002), "Discurso médico, cultura higiénica y la mujer en la ciudad de México al cambio de siglo (XIX-XX)", Estudios Mexicanos, núm.18, diciembre, pp. 1-22.

Bayle, A y H. Hollard (1828), Manual de anatomía general o descripción sucinta de los tejidos primitivos que comprenden los órganos del hombre, Traducción al castellano por Cayetano Balseyro, Imprenta que fue de Fuentenebro, Madrid.

Bernard, Claude (1858a), Leçons sur les effets des substances toxiques et médicamenteuses, Baillière, París. (1858b), Leçons sur la physiologie et la pathologie du système nerveux, Collège de France, París.

Bernheim, H. (1913), L'hystérie, O. Doin et fils, París.

Bichat, Francisco (1807), Anatomía general aplicada a la fisiología y a la medicina, Traducido al castellano por Ramón Truxillo, Imprenta de la hija de Ibarra, Madrid.

Bojalil, Andreé (2013), El desarrollo de la psiquiatría en Puebla en el siglo xix y principios del Xx. Tesis de doctorado, Universidad Iberoamericana, México.

(2018), "Médicos contra jueces: la responsabilidad y la incapacidad de los individuos en los juicios de interdicción en la Puebla del Porfiriato", Antrópica Revista, 26 de abril de 2018, pp. 105-130. 
(2018b), "La libertad de la crápula. Liberales y católicos en contra del alcoholismo en Puebla durante el porfiriato.", Oficio. Revista de historia e interdisciplina, 7, julio-diciembre 2018, pp. 61-78.

Bourneville, M. (1898), Estudios clínicos y terapéuticos sobre las enfermedades del sistema nervioso, Tercera edición, Felix Alcan, París.

Bouchut, E. (1866), Du diagnostic des maladies du système nerveux par l'ophthalmoscopie, Germer Bailliere, París.

(1880), Ophtalmoscopie et Cerebroscopie, s.ed., París.

Boisseau, Edmond (1870), Des Maladies Simulées et Des Moyens de Les Reconnaïtre: Lecons Professées Au Val-de Grace, J.B. Bailliere et Fils, París.

Briggs, Laura (2000), "The Race of Hysteria: Overcivilization and the Savage, Woman in Late NineteenthCentury Obsterics and Gynecology", American Quarterly, núm.52, junio, pp. 246-273.

Briot, Charles (1842), Theorie matematique de la lumière, Mallet-Bachellier, París.

Briquet, P. (1859), Traité clinique et thérapeutique de l'hystérie, Baillière et Fils, París.

Canguilhem, Georges (1978), Lo normal y lo patológico, Siglo XXI, México.

Capurón, Joseph (1813), Traité des maladies des enfans, jusqu' á la puberté, Chez l'áuteur dans Crouliebois, París.

Cárdenas, J. et al. (2015), "La medicina en el siglo XIX", en J. Gaspar Cortés Riveroll (coord.), Historia y filosofía de la medicina, BUAP, Puebla, pp. 271-304.

Carrillo, Ana María y Juan José Saldaña (2005), "La enseñanza de la medicina en la Escuela Nacional durante el Porfiriato”, en Juan José Saldaña (coord.), La casa de Salomón en México. Estudios sobre la institucionalización de la docencia y la investigación científicas, UNAM, México, pp. 257-282.

Castro, Efraín (2009), "La Escuela de Medicina de Puebla", Tiempo universitario. Gaceta histórica de la BUAP, núm.8, junio, pp. 1-7.

Cazeaux, P. (1852), Tratado teórico y práctico del arte obstetricia (3 tomos), Imprenta de Matute, Madrid.

Charcot, J. (1882), Lecciones sobre el sistema nervioso dadas en la Salpêtrière. $1^{a}$ y $2^{a}$ parte, Tercera edición, A. Pérez, Madrid.

Chaussier, Francois (1820), Recueil Anatomique á lúsage des jeunes gens qui se destinent á létude de la chirurgie, de la médicine, de la peintureet de lasculpture avec des explications suivant la nouvelle nomenclature máthidique, et des tables synonymiques on a p’r réré les planches anatomiques d’albinus, Caille de Raviers, París.

Colin, H. (1890), Essai sur l'état mental des hystériques, J. Rueff, París.

Cortés, Gaspar (2010), Historia de la medicina en Puebla, BUAP, Puebla.

y Dulce María Palacios (2012), Historia de la medicina en Puebla durante la intervención francesa, BUAP, Puebla.

Cruz, Nydia (1995), "La proyección de los nuevos saberes. El Departamento de Antropología Criminal de Puebla en el siglo XIX", Estudios de antropología biológica, vol. 5, pp. 451-467.

Del Río, Isaac (1898), Algunas consideraciones del alcohol como veneno. Trabajo que para el examen profesional de medicina, cirugía y obstetricia presenta Isaac del Río, Tip Franco $1^{a}$ de Santa Teresa número 3, Puebla

Despine, Phillipe (1875), De la Folie, París.

Didi-Huberman, Georges (2007), La invención de la histeria. Charcot y la iconografía fotográfica de la Salpêtrière, Ediciones Cátedra, Madrid.

Dujardin, Félix (1831), Mémoire sur les couches du sol en Touraine et descriptions des coquilles de la craie des faluns, F.-G. Levrault, París.

(1841), Histoire naturelle des zoophytes. Infusoires, comprenant la physiologie et la classification de ces animaux, et la manière de les étudier à l'aide du microscope, Roret, París.

Dujardin, Félix (1843), Nouveau manuel de l'observateur au microscope, Roret, París. 
Dujardin-Beaumetz, Georges (1879-1883), Leçon de clinique thérapeutique, s.ed., París. (1887), Les nouvelles médications, O. Doin, París. (1893), Formulaire pratique de thérapeutique et de pharmacologie, O. Doin, París.

Dujardin-Beaumetz, Georges, Charles-Marie Debierre y Godefroy Bardet (eds.)(1883-1895), Dictionnaire de thérapeutique, de matière médicale, de pharmacologie, de toxicologie et des eaux minérales, O.Doin, París.

Echegaray, José (1873), Teorías modernas de la física, Imprenta y esteriotipia de M. Rivadeneyra, Madrid. Espinosa, Ernesto (1885), Ligeras consideraciones sobre los artículos del código penal del estado, relativos a la embriaguez, Tesis, Imprenta y Litografía de J.M. Osorio. Calle de Santa Clara num. 6, Puebla.

Esquirol, Etienne (1854), Enfermedades mentales, Madrid

Fajardo, Guillermo (2002), "Un pasado con mucho presente. El Hospital Real de San Pedro en Puebla de los Ángeles", Cir Ciruj, núm. 70, noviembre-diciembre, pp. 459-467.

Falret, Jules (1890), Études cliniques sur les maladies mentales et nerveuses, Baillére, París.

Fernández, Rosa (2015), Las tesis universitarias en México. Una tradición y un patrimonio en vilo, UNAM, México.

Foucault, Michael (2005), El poder psiquiátrico, Ediciones Akal, Madrid.

Freedman, Estelle (1982), "Sexuality in Nineteenth-Century America: Behavior, Ideology, and Politics", Reviews in American History, núm.10, diciembre, pp. 196-215.

Gaillard, Thomas (1879), Traité clinique des maladies des femmes, H. Lauwereyns, París.

Galindo, José Agustín (1897), Apuntes sobre el alcoholismo. Tesis que presenta al jurado calificador, en su examen profesional, el alumno José Agustín Galindo, Tesis, Imprenta del Hospital General, Puebla.

Gilles de la Tourette, Georges (1891), Traité Clinique et Thérapeutique de l'Hystérie d'aprés l'enseignement de La Salpêtrière, E. Plon, Nourrit et Cie, París.

Gorbach, Frida (2007), "El encuentro de un monstruo y una histérica. Una imagen para México a finales del siglo XIX", Nuevo Mundo Mundos Nuevos. Débats, "La influencia de ultramar. Medicina y Sociedad en México, siglos XIx y Xx", Dossier coordinado por Rosalina Estrada Urroz, documento html disponible en: <http://nuevomundo.revues.org/index3123.html> (fecha de consulta: 3/05/2009).

(2008), "Los caprichos de la histeria: cuadros para una identidad", Historia y Grafía, núm. 31, julio-diciembre, pp. 77-101.

(2013), "Salir del difusionismo", Maguare, núm. 27, enero- junio, pp. 51-70.

y Matthew Train (2005), "From the Uterus to the Brain: Images of Hysteria in NineteenthCentury Mexico", Feminist Review, núm.79, marzo, pp. 83-99.

Grasset, Joseph (1889), "Hystérie", Dictionnaire Encyclopédique des Sciences Médicales, Asselin et Houzeau, París.

Guerrero, Julio (1901), La génesis del crimen en México, Librería de la Vda. De CH. Bouret, México.

Hidalgo y Carpio, Luis (1877), Compendio de Medicina Legal arreglado a la legislación del Distrito Federal, Imprenta de Escalante, México.

Huertas, Rafael (1999), "Entre la doctrina y la clínica: la nosografía de J.E.D. Esquirol (1772-1840)", Cronos, no. 2 (1), pp. 47-66.

(2014), ¿Qué sabemos de la locura?, Catarata, Madrid.

Jiménez, Miguel (1866), "Alcoholosis", Gaceta Médica de México, t. II, núm. 7, $1^{\circ}$ de abril de 1866, pp. 97-108.

Kraepelin, Emile (1901), Einführung in die psychiatrische Klinik, Johann Ambrosius Barth, Leipzig.

Labastida, Sebastián (1879), "Acción del alcoholismo más allá del individuo", Gaceta Médica de México,

t. XIV, núm. 15, $1^{\circ}$ de agosto de 1879, pp. 305-311. 
Lasègue, Ernest-Charles (1873), "De l'anorexie hystérique", Archives générales de médecine, abril, pp. 385-403.

Legrand, Saulle (1874), Traité de médecine legale, de jurisprudence médicale et de toxicologie, A. Delahaye, París.

Lewes, Georges (1875), Problems of life and mind, Trübner and Co., Londres.

Libbrecht, Katrien (1995), Hysterical psychosis: a historical survey, Transaction, Londres.

Longet, François-Achille (1842), Anatomie et physiologie du système nerveux de l'homme et des animaux vertébrés : ouvrage contenant des observations pathologiques relatives au système nerveux et des expériences sur les animaux des classes supérieures, Fortin, París.

Lorenzo, María Dolores (2011), El estado como benefactor. Los pobres y la asistencia pública en la Ciudad de México (1877-1905), El Colegio Mexiquense, El Colegio de México, México.

Magendie, François (1828), Compendio elemental de fisiología, traducido al castellano por Ramón Frau Trias, Imprenta de la viuda e hijos de Antonio Brusí, Barcelona.

Magnan, Valentín (1871), Étude expérimentale et clinique sur l'alcoolisme, alcool et absinthe; épilepsie absinthique, Impr. de Renou et Maulde, París.

(1873), De l'hémi-anesthésie, de la sensibilité générale et des sens dans l'alcoolisme chronique,Imp. De Martinet, París. (1873)

(1874), De l'alcoolisme, des diverses formes de délire alcoolique at de leur traitement, Delahaye, París.

y P.-M. Legrain (1895), Les dégénéres. Etat mental et síndrome épisodiques, Rueff, París.

Manquat, Alexandre (1898), Traité Elementaire de Thérapeutique de Matiere Medicale et de Pharmacologie, Troisième édition, París.

Marcè, Victor (1858), Traité de la Folie des femmes enceintes, desnouvelles accouchées et des nourrices, J.B. Baillière et Fils, París.

(1862), Traité pratique des maladies mentales, J.B. Baillière et Fils, París.

Martínez, Fernando (2003), La medicina científica y el siglo xIx mexicano. Fondo de Cultura Económica, México.

Mata, Pedro (1864), Razón humana en sus Estados Intermedios. s.ed., Madrid.

Mejía, Demetrio (1878), "Clínica interna", Gaceta Médica de México, t. XIV, núm 14, 15 de julio de 1879, p. 476.

(1896), "Clínica Interna. Sobre la histeria" Gaceta Médica de México, t. XXXIII, núm. 10, $1^{\circ}$ de julio de 1896, p.462.

Mendizábal, José de (2009), Los almanaques poblanos y las Efemérides de Puebla de José de Mendizábal Tamborrel, Carlos Contreras y Claudia Pardo (comp.), BUAP, Puebla.

Menville, Charles (1858), Histoire Philosophique Et Medicale de La Femme: Consideree Dans Toutes Les Epoques Principales de La Vie, J.B Bailliere et Fils, París.

Micale, Mark (1993), "On the disappearance of Hysteria: A Study in the Clinical Deconstruction of a Diagnosis", Isis, núm. 84, marzo, pp. 496-526.

Morales, Samuel y Secundino Sosa (1888), Puebla su higiene sus enfermedades, Oficina Tip. de la Secretaría de Fomento, México.

Morantz, Regina M. y Sue Zschoche (1980), "Professionalism, Feminism, and Gender Roles: A Comparative Study of Nineteenth-Century Medical Therapeutics", The Journal of American History, núm. 67, diciembre, pp. 568-588.

Morel, Augusto (1857), Traité des dégénérescences physiques, intellectuels et morales de l'espèce humaine et des causes qui produisent ces variétés maladives, B. Baillière, París.

y Mathias Duval (1875), Manuel de I'anatomiste: anatomie descriptive et dissection, Asselin, París.

Newton, Isaac (1779), Philosophice naturalis principia mathematica, s.ed., Londres. 
Olvera, José (1870), "Discurso sobre las causas de las neurosis en México", El Observador Médico, t. I, núm. 4, p. 55.

Ortega, José de Jesús (1885), Algunas observaciones sobre el alcoholismo, Tesis, Imprenta de Ibáñez y Lamarque, Puebla.

Pasalagua, M. (1874), "Higiene de las bebidas alcohólicas y sus efectos inmediatos en México", Gaceta Médica de México, t. IX, núm. 3, $1^{\circ}$ de febrero de 1874, pp. 37-46.

Pérez Montfort, Ricardo (2016), Tolerancia y Prohibición, Debate, México.

Piccato, Pablo (1995), "El Paso de Venus por el disco del sol. Criminality and Alcoholism in the Late Porfiriato", Historia Mexicana, vol.47, núm.1, pp. 133-181.

(1997), "La construcción de una perspectiva científica: miradas porfirianas a la criminalidad", Estudios Mexicanos, núm.11, octubre-diciembre, pp. 203-241.

Pinel, Phillipe (1809), Traité médico-philosophique sur l'aliénation mentale, Chez J. Ant Brosson, París.

Ponce, Fernando (1911), El alcoholismo en México, Antigua Imprenta de Murguía, México.

Reglamento para el Estudio y Ejercicio de las Ciencias Médicas (1856), Imprenta de José María Macías, Puebla.

Reglamento para el gobierno interior de la Escuela de Medicina y Farmacia del Estado de Puebla (1879), Imprenta del Hospicio, Puebla.

Reglamento para las escuelas primarias elementales del Estado de Puebla (1893), Imprenta de la Escuela de Artes y Oficios, Puebla.

Ribot, Thomas (1875), Psychologie anglaise contemporaine, G. Bailliere, París.

Richerard, Anthelme (1802), Nouveaux Élémens de Physiologie, de límprimiere d’Hacquar, Chez Crapart,

Caille et Ravier, Libraires, $2^{a}$ edición revisada, corregida y ampliada, París.

Richet, Charles (1882), Physiologie des muscles et des nerfs, Bailliere, París.

Robles, Rosario (2004), "Rafael Serrano: la consagración de un hombre de ciencia, digno egresado del Colegio del Estado", Archivo Histórico de la BUAP, núm. 10, junio, documento html disponible en: <http://www.archivohistorico.buap.mx/tiempo/2004/a7g10.htm\#10p> (fecha de consulta: 15/05/2017).

(2012), En Puebla médicos, ciencia y academia (1850-1910). El estudio de la clínica hospitalaria, BUAP, UPAEP, Puebla.

Rodiles, Francisco (1885), Breves apuntes sobre la histeria seguidos de un apéndice sobre la locura histérica, Tesis, Imprenta de Miguel Corona, Puebla.

Rougmanac, Carlos (1904), Los criminales en México: ensayo de psicología criminal, El Fénix, México.

Ruíz, Luis (1891), "Algunas consideraciones sobre el alcoholismo", Gaceta Médica de México, t. XXVI, núm. 1, $1^{\circ}$ de enero de 1891, pp. 2-7.

Sánchez, Trinidad (1896), El alcoholismo en la República Mexicana. Discurso pronunciado en la sesión solemne que celebraron las Sociedades Cientificas y Literarias de la Nación, el día 5 de Junio de 1896, Imprenta del Sagrado Corazón de Jesús, México.

Serrano, Rafael (1884), Fragmentos de psiquiatría óptica, Tesis, Imprenta de Miguel Corona, Puebla.

Sociedad Española de Beneficencia de Puebla (1923), "Historia del Hospital Beneficencia Española de Puebla", Junta Directiva de la Sociedad Española de Beneficencia de Puebla, documento html disponible en: <http://www.beneficenciaespanola.com.mx/historia/> (fecha de consulta: 12/06/2017).

Somolinos, Germán (1976), Historia de la psiquiatría en México, SepSetentas, México.

Sosa, Secundino (1901), "Embriaguez y dipsomanía", Gaceta Médica de México, 13 de enero de 1901, pp. 20-36.

Sydenham, Thomas (1676), Observationes medicae, G. Kettilby, Londres. 
Vicencio, Daniel (2014), "Locos criminales en los años del Porfiriato. Los discursos científicos frente a la realidad clínica, 1895-1910", Estudios de historia moderna y contemporánea de México, vol. 47, enero- junio, pp. 79-119.

Vulpian, Ernest (1866), Leçons sur la physiologie du systeme nerveux, Germer Baillière Libraire-Éditeur, París.

Willis, Thomas (1667), Pathologiae Cerebro et Nervosi Generis Specimen, s.ed., Londres.

Zacarías-Prieto, Jorge (2015), "La escuela nacional de medicina en el siglo XIX", en J. Gaspar Cortés Riveroll (coord.), Historia y filosofía de la medicina, BUAP, Puebla, pp. 305-318.

André Bojalil Daou es investigadora del Centro de Investigación y Docencia Económicas (CIDE). Sus líneas de investigación son la historia de la psiquiatría en Puebla siglos XIX y XX y la arqueología histórica. Entre sus publicaciones recientes están "La vida cotidiana en los hospitales de dementes mexicanos: el caso de San Roque", Revista Historia 2.0, Conocimiento histórico en clave digital. Dossier Historia del crimen, la prevención y el castigo, núm. 5., junio 2013, pp. 66-77 (http://historia2.0.historiaabierta.org/), y "Relaciones de consumo de dos ranchos fronterizos sonorenses de la primera mitad del siglo xx", Revista Anuario de Historia Regional y de las Fronteras, vol. 18, núm. 1 (enero-junio de 2013), pp. 63-84 (http://revistas.uis.edu. co/index.php/anuariohistoria/article/view/3412).

Recibido: 6 de julio de 2017

Aceptado: 14 de abril de 2018 